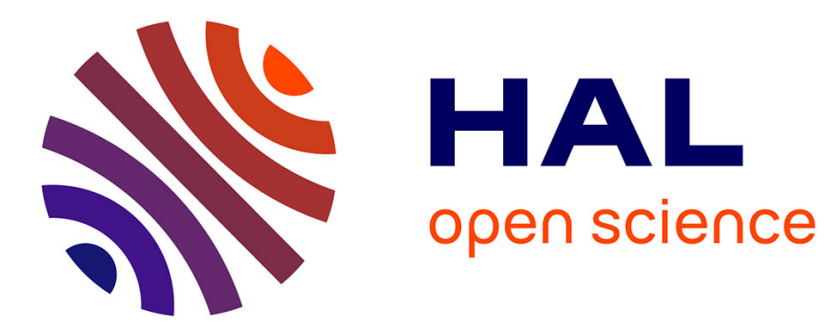

\title{
A metal-radical hetero-tri-spin SCM with methyl-pyrazole-nitronyl nitroxide bridges
}

Xiaohui Huang, Kang Wang, Jing Han, Junfang Xie, Licun Li, J. P. Sutter

\section{To cite this version:}

Xiaohui Huang, Kang Wang, Jing Han, Junfang Xie, Licun Li, et al.. A metal-radical hetero-tri-spin SCM with methyl-pyrazole-nitronyl nitroxide bridges. Dalton Transactions, 2021, 50 (34), pp.1199211998. 10.1039/D1DT02006D . hal-03361525

\section{HAL Id: hal-03361525 \\ https://hal.science/hal-03361525}

Submitted on 1 Oct 2021

HAL is a multi-disciplinary open access archive for the deposit and dissemination of scientific research documents, whether they are published or not. The documents may come from teaching and research institutions in France or abroad, or from public or private research centers.
L'archive ouverte pluridisciplinaire HAL, est destinée au dépôt et à la diffusion de documents scientifiques de niveau recherche, publiés ou non, émanant des établissements d'enseignement et de recherche français ou étrangers, des laboratoires publics ou privés. 


\title{
Metal-radical hetero-tri-spin SCM with methyl-pyrazole-nitronyl nitroxide bridges
}

Xiaohui Huang, ${ }^{\text {a }}$ Kang Wang, ${ }^{\text {a }}$ Jing Han, ${ }^{a}$ Junfang Xie, ${ }^{a}$ Licun Li ${ }^{* a}$ and Jean-Pascal Sutter ${ }^{*}$

a Department of Chemistry, Key Laboratory of Advanced Energy Materials Chemistry, College of Chemistry, Nankai University, Tianjin 300071, China

${ }^{b}$ Laboratoire de Chimie de Coordination du CNRS (LCC-CNRS), Université de

Toulouse, CNRS, Toulouse, France

*Corresponding author.E-mail address: llicun@nankai.edu.cn

sutter@lcc-toulouse.fr

\begin{abstract}
The preparation, crystal structures, and magnetic properties of a family of hetero-tri-spin 1-D coordination polymers with formula $\left[\mathrm{Ln}(\mathrm{hfac})_{3} \mathrm{Cu}(\mathrm{hfac})_{2}(4-\mathrm{NIT}-\mathrm{MePyz})_{2}\right] \quad(\mathrm{Ln}=\mathrm{Gd}, \mathbf{1}, \mathrm{Tb}, \mathbf{2}, \mathrm{Dy}, \quad 3 ;$ hfac = hexafluoroacetylacetonate; 4-NIT-MePyz $=2-\{4-(1$-methyl)-pyrazolyl $\}-4,4,5,5-$ tetramethylimidazoline-1-oxyl-3-oxide) are reported. In these complexes, the 4-NIT-MePyz radical acts as a linker to bridge the $\mathrm{Cu}^{\mathrm{II}}$ and $\mathrm{Ln}^{\mathrm{III}}$ ions through its pyrazole and aminoxyl groups to form chain structure. Magnetic properties typical for spin-chains are observed for Dy and $\mathrm{Tb}$ derivatives but single-chain magnet (SCM) behavior was evidenced only for $\mathrm{Tb}$ compound which is characterized by an energy gap for demagnetization of $\Delta_{\tau} / k_{\mathrm{B}}=31 \mathrm{~K}$.
\end{abstract}

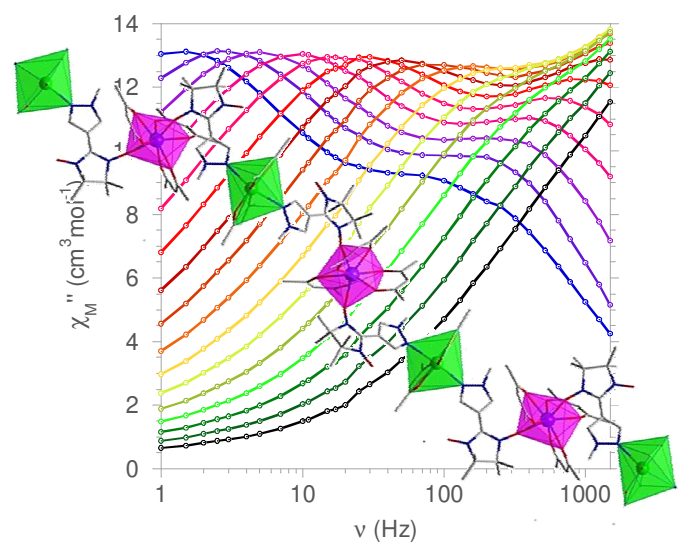




\section{Introduction}

The combination of metal ions and radical units is a well established approach for designing magnetic molecular materials. ${ }^{1-3}$ This strategy was successfully applied to produce a number of $3 \mathrm{D}$ magnets with high $T_{\mathrm{c}}$ temperature, ${ }^{4-10}$ and molecular nanomagnets, ${ }^{11,12}$ i.e. single-molecule magnets (SMMs) and single-chain magnets (SCMs), which have crucial potential applications in spintronics and magnetic memory. ${ }^{13-18}$ Remarkable results comprise the first SCM, $\left[\mathrm{Co}(\mathrm{hfac})_{2}(\mathrm{NIT}-\mathrm{PhOMe})\right],{ }^{12}$ and a binuclear $\mathrm{Tb}$ complex linked by a $\mathrm{N}_{2}{ }^{3-}$ radical exhibiting blocking for a temperature as high as $20 \mathrm{~K} .^{19}$

In this context, the search for new heterospin materials for tuning the magnetic behaviors or unveiling original physics is an important task. An emerging design strategy concerns hetero-tri-spin $(2 p-3 d-4 f)$ complexes, in which a favorable combination of magnetic anisotropy and magnetic exchanges could be achieved. ${ }^{20-23}$ The combination of three different spins centers provides enhanced versatility for modulating the magnetic properties of the system. In this context, radical derivatives with ancillary ligand moieties are required to support multimetal coordination, i.e. capable to act as linkers. For instance, an N-heterocycle-substituted nitronyl nitroxide possesses both $\mathrm{N}$ (from heterocyclic unit) and $\mathrm{O}$ (from nitroxide group) donors that can coordinate to transition metal and the lanthanide ion. Following the HSAB principle, the coordination can be metal-selective making such a ligand a good candidate to act as a paramagnetic bridge in $2 p-3 d-4 f$ complexes. Heterospin complexes made of pyrazole substituted nitronyl nitroxides ligands and $\mathrm{Cu}(\mathrm{hfac})_{2}$ have been extensively studied because of the thermally and optically induced spin crossover-like magnetic behaviors they may exhibit. ${ }^{24-29}$ Herein this $\mathrm{Cu}$-Radical system has been associated to $\operatorname{Ln}(\mathrm{III})$ ions to obtain a family of hetero-tri-spin chains with the formula $\left[\mathrm{Ln}(\mathrm{hfac})_{3} \mathrm{Cu}(\mathrm{hfac})_{2}(4-\mathrm{NIT}-\mathrm{MePyz})_{2}\right](\mathrm{Ln}=\mathrm{Gd} \mathbf{1}, \mathrm{Tb} 2$, Dy 3; hfac = hexafluoroacetylacetonate; 4-NIT-MePyz $=2$-\{4-(1-methyl)-pyrazolyl $\}$ - 4,4,5,5tetramethylimidazoline-1-oxyl-3-oxide) in which the 4-NIT-MePyz radical (Scheme 1) acts as a magnetic linker between the $\mathrm{Cu}^{\mathrm{II}}$ and $\mathrm{Ln}^{\mathrm{III}}$ ions through its pyrazole and 
aminoxyl groups, respectively. The $\mathrm{Tb}$ derivative was found to behave as SCM, demonstrating the suitability of this strategy for designing 1D-molecular nanomagnets.

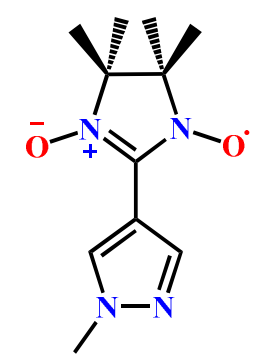

Scheme 1. The structure of the 4-NIT-MePyz radical.

\section{Experimental Section}

\section{Materials}

All reagents and solvents for chemical reactions were commercially supplied and used without further purification. The radical ligand 4-NIT-MePyz was synthesized according to previous reports in the literature. ${ }^{30}$

\section{Physical Measurements}

Elemental analyses $(\mathrm{C}, \mathrm{H}, \mathrm{N})$ were obtained with a Perkin-Elmer 240 elemental analyzer. IR spectra ( $\mathrm{KBr}$ pellets) were recorded on a Bruker Tensor 27 spectrophotometer in the region 4000-400 $\mathrm{cm}^{-1}$. Powder X-ray diffraction (PXRD) data for the as-synthesized complexes were collected on a Rigaku Ultima IV diffractometer. Magnetic measurements were carried out with a Quantum Design MPMS 5S SQUID magnetometer in the temperature range 2-300 K. The investigations were performed on crystalline powders of the complexes mixed with grease (except for Gd) and hold in a gelatin capsule. The temperature dependences of the magnetization were collected in an applied field of $1 \mathrm{kOe}$ (or as stated) and the isothermal field dependence of the magnetizations were measured up to $5 \mathrm{~T}$. The molar susceptibility $\left(\chi_{\mathrm{M}}\right)$ was systematically corrected for sample holder, grease (if applicable) and for the diamagnetic contribution of all the atoms by using Pascal's tables. ${ }^{31} \mathrm{AC}$ susceptibility has been collected in the AC frequency range $1-1500 \mathrm{~Hz}$ in zero field and with applied field. 


\section{Preparation of [ $\left.\operatorname{Ln}(\text { hfac })_{3} \mathrm{Cu}(\mathrm{hfac})_{2}(4-\mathrm{NIT}-\mathrm{MePyz})_{2}\right](\mathrm{Ln}=\mathrm{Gd} 1$, Tb 2, and Dy 3)}

Complexes 1-3 were synthesized by the following method : $\mathrm{Ln}(\mathrm{hfac})_{3} \cdot 2 \mathrm{H}_{2} \mathrm{O}(0.1$ mmol $)$ and $\mathrm{Cu}(\mathrm{hfac})_{2}(0.1 \mathrm{mmol})$ were dissolved in hot heptane $(20 \mathrm{~mL})$, then the solution was kept refluxing for 4 hours. Subsequently, dry $\mathrm{CH}_{2} \mathrm{Cl}_{2}(5 \mathrm{~mL})$ solution containing 4-NIT-MePyz radical $(0.2 \mathrm{mmol})$ was slowly added. The mixture was maintained at reflux for another 30 minutes, then cooled and filtered. The filtrate was kept evaporating at room temperature for 5 days, and then deep blue block crystals were collected.

[Gd(hfac $\left.)_{3} \mathbf{C u}(\text { hfac })_{2}(4-N I T-M e P y z)_{2}\right]$ (1): Yield: $57 \%$. Elemental analysis for $\mathrm{C}_{47} \mathrm{H}_{39} \mathrm{CuGdF}_{30} \mathrm{~N}_{8} \mathrm{O}_{14}$ (3464.64) : calcd: C 32.62, H 2.27, N 6.47; found: C 32.89, H 2.62, N 6.43\%. IR (KBr, $\left.\mathrm{cm}^{-1}\right)$ : 1650(s), 1610(w), 1558(m), 1530(m), 1503(w), 1484(w), 1463(w), 1352(m), 1254(s), 1196(s), 1138(s), 1095(w), 1018(m), 951(w), 871(w), 797(s), 761(w), 742(m), 678(m), 660(s).

[Tb(hfac) $\left.)_{3} \mathbf{C u}(\mathbf{h f a c})_{2}(4-N I T-M e P y z)_{2}\right]$ (2): Yield: $61 \%$. Elemental analysis for $\mathrm{C}_{47} \mathrm{H}_{39} \mathrm{CuTbF}_{30} \mathrm{~N}_{8} \mathrm{O}_{14}$ (3461.30) : calcd: C 32.59, H 2.27, N 6.47; found: C 32.47, H 2.31; N 6.40\%. IR (KBr, $\left.\mathrm{cm}^{-1}\right): 1650(\mathrm{~s}), 1609(\mathrm{w}), 1558(\mathrm{~m}), 1530(\mathrm{~m}), 1504(\mathrm{w})$, 1482(w), 1462(w), 1355(m), 1254(s), 1196(s), 1138(s), 1097(w), 1018(m), 951(w), 871(w), $797(\mathrm{~s}), 760(\mathrm{w}), 741(\mathrm{~m})$, 681(m), 662(s).

[Dy(hfac $\left.)_{3} \mathbf{C u}(\text { hfac })_{2}(4-N I T-M e P y z)_{2}\right]$ (3): Yield: 60\%. Elemental analysis for $\mathrm{C}_{47} \mathrm{H}_{39} \mathrm{CuDyF}_{30} \mathrm{~N}_{8} \mathrm{O}_{14}$ (3471.80) : calcd: C 32.52, H 2.26, N 6.46; found: C 32.74, H 2.51, N 6.50\%. IR (KBr, cm $\left.{ }^{-1}\right): 1650(\mathrm{~s}), 1610(\mathrm{w}), 1558(\mathrm{~m}), 1530(\mathrm{~m}), 1506(\mathrm{w})$, 1485(w), 1463(w), 1353(m), 1255(s), 1193(s), 1138(s), 1098(w), 1019(m), 951(w), 872(w), 798(s), 761(w), 742(m), 679(m), 660(s).

The phase purities of the bulk samples of 1-3 are were confirmed by PXRD (Fig. S9).

\section{X-ray Crystallography}

Crystallographic data for complexes 1-3 were acquired on a Rigaku Saturn CCD diffractometer using graphite-monochromated Mo-K $\alpha$ radiation $(\alpha=0.71073 \AA$ ) at $113 \mathrm{~K}$. The structure was solved by direct methods and subsequently completed by refinement using full-matrix least square methods based on $\mathrm{F}^{2}$ employing the 
SHELXS-2014 and SHELXL-2014. ${ }^{32,33}$ Non-hydrogen atoms were refined anisotropically, and the $\mathrm{H}$ atom positions were geometrically placed. Disordered $\mathrm{F}$ and $\mathrm{C}$ atoms were kept at appropriate positions by using commands of ISOR and SIMU. Crystallographic refinement details for complexes 1-3 are shown in Table 1. The significant bond lengths and angles are given in Tables S1-S3. These data of 1-5 can be obtained freely with CCDC numbers 2085682-2085684.

Table 1. Crystallographic data and structure refinement summary for 1-3.

\begin{tabular}{|c|c|c|c|}
\hline Complex & 1 & 2 & 3 \\
\hline Empirical formula & $\mathrm{C}_{94} \mathrm{H}_{78} \mathrm{Cu}_{2} \mathrm{~F}_{60} \mathrm{Gd}_{2} \mathrm{~N}_{16} \mathrm{O}_{28}$ & $\mathrm{C}_{94} \mathrm{H}_{78} \mathrm{Cu}_{2} \mathrm{~F}_{60} \mathrm{~Tb}_{2} \mathrm{~N}_{16} \mathrm{O}_{28}$ & $\mathrm{C}_{94} \mathrm{H}_{78} \mathrm{Cu}_{2} \mathrm{~F}_{60} \mathrm{Dy}_{2} \mathrm{~N}_{16} \mathrm{O}_{28}$ \\
\hline$M, \mathrm{~g} \cdot \mathrm{mol}^{-1}$ & 3461.30 & 3464.64 & 3471.80 \\
\hline$T / \mathrm{K}$ & 113 & 113 & 113 \\
\hline Crystal system & triclinic & triclinic & triclinic \\
\hline Space group & $\mathrm{P}_{\overline{1}}$ & $\mathrm{P}_{\overline{1}}$ & $\mathrm{P}_{\overline{1}}$ \\
\hline$a / \AA$ & $14.5495(7)$ & $14.5042(5)$ & $14.544(3)$ \\
\hline$b / \AA$ & $22.989(1)$ & $22.9100(8)$ & $23.084(5)$ \\
\hline$c / \AA ̊$ & $25.262(1)$ & $25.2112(9)$ & $25.331(5)$ \\
\hline$\alpha / /^{\circ}$ & $113.252(4)$ & $112.959(3)$ & $113.05(3)$ \\
\hline$\beta /^{\circ}$ & $94.091(4)$ & $94.439(3)$ & $94.12(3)$ \\
\hline$\gamma /{ }^{\circ}$ & $107.833(5)$ & $107.849(3)$ & $108.15(3)$ \\
\hline$V / \AA^{3}$ & $7209.5(6)$ & $7154.7(5)$ & $7251(3)$ \\
\hline$Z$ & 2 & 2 & 2 \\
\hline$D_{\text {calcd }} / \mathrm{g} \cdot \mathrm{cm}^{-3}$ & 1.594 & 1.608 & 1.590 \\
\hline$\mu / \mathrm{mm}^{-1}$ & 1.343 & 1.415 & 1.451 \\
\hline$\theta /^{\circ}$ & $1.671-25.010$ & $1.578-26.373$ & $1.481-25.008$ \\
\hline$F(000)$ & 3408 & 3412 & 3416 \\
\hline Reflections collected & 66500 & 76660 & 58566 \\
\hline Unique reflns $/ R_{\mathrm{int}}$ & $25403 / 0.1574$ & $29211 / 0.0777$ & $24787 / 0.0710$ \\
\hline GOF & 0.982 & 1.012 & 1.163 \\
\hline$R_{1}, w R_{2}(I>2 \sigma(I))$ & $0.1009,0.2608$ & $0.0652,0.1643$ & $0.0730,0.1935$ \\
\hline$R_{1}, w R_{2}$ (all data) & $0.1491,0.3165$ & $0.1109,0.1896$ & $0.1017,0.2265$ \\
\hline
\end{tabular}

${ }^{\mathrm{a}} R_{1}=\Sigma(\|F \mathrm{O}|-| F \mathrm{c}\|) / \Sigma|F \mathrm{o}|, w R_{2}=\left[\Sigma w\left(|F \mathrm{o}|^{2}-|F \mathrm{c}|^{2}\right)^{2} / \Sigma w\left(|F \mathrm{o}|^{2}\right)^{2}\right]^{1 / 2}$ 


\section{Results and Discussion}

\section{Description of the Crystal Structures}

\section{$\left[\operatorname{Ln}(\text { hfac })_{3} \mathrm{Cu}(\mathrm{hfac})_{2}(4-\mathrm{NIT}-\mathrm{MePyz})_{2}\right](\operatorname{Ln}=\mathrm{Gd} 1, \mathrm{~Tb} 2$, and Dy 3)}

Complexes 1-3 are isostructural and belong to the triclinic $P \overline{1}$ space group. They all display a hetero-tri-spin chain structure. It's worth noting that a series of hetero-tri-spin complexes of formula $\left[\mathrm{Ln}_{2} \mathrm{Cu}_{3}(\mathrm{hfac})_{12}(4-\mathrm{NIT}-\mathrm{MePyz})_{4}\right]$ have been obtained with the same reagents but in milder reaction conditions $\left(80^{\circ} \mathrm{C}\right){ }^{34}$ The asymmetric structural unit of complexes $\mathbf{1 - 3}$ consists of two $\mathrm{Ln}^{\mathrm{III}}$ ions, two $\mathrm{Cu}^{\mathrm{II}}$ ions and four 4-NIT-MePyz radicals. Complex $\mathbf{1}$ is selected as a representative example to describe the structure, a view of the molecular assemblage is shown in Figure 1, the related views and data for complexes $\mathbf{2}$ and $\mathbf{3}$ are given in SI.

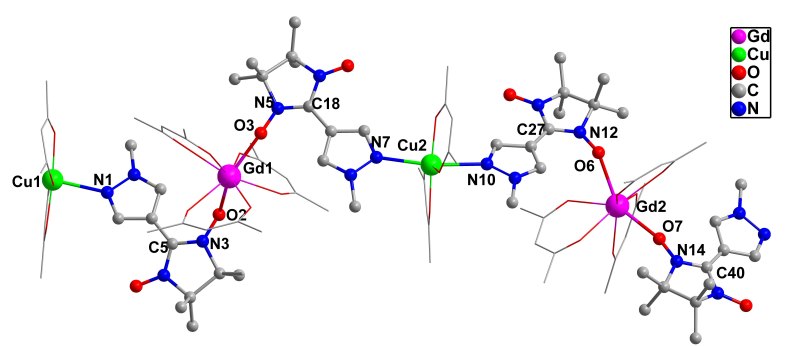

Figure 1. The asymmetric unit of complex $\mathbf{1} . \mathrm{H}$ and $\mathrm{F}$ atoms are not shown for the sake of clarity.

The $\mathrm{Gd}^{\mathrm{III}}$ ion is coordinated by six oxygen atoms from three chelating hfac coligands and two oxygen atoms of NO groups from two radicals. The $\mathrm{Gd}-\mathrm{O}(\mathrm{rad})$ bond distances are in the range of 2.299(7)-2.372(7) $\AA$, which are slightly shorter than those of the discrete complex (i.e. Gd-O: 2.354(4), 2.382(3) $\AA$ ). ${ }^{34}$ The $\mathrm{Gd}-\mathrm{O}(\mathrm{hfac})$ bond lengths range from $2.356(7) \AA$ to $2.448(7) \AA$, which are comparable to the $\mathrm{Ln}-\mathrm{O}(\mathrm{hfac})$ distances reported in the literature. ${ }^{34-37}$ The $\mathrm{O}(\mathrm{rad})-\mathrm{Gd}-\mathrm{O}(\mathrm{rad})$ angles are $145.6(3)^{\circ}$ and $140.3(2)^{\circ}$, respectively. The Gd-O-N-C torsion angles are $90.9(1)^{\circ}$ for $\mathrm{Gd}_{1}-\mathrm{O}_{2}-\mathrm{N}_{3}-\mathrm{C}_{5}, 69.8^{\circ}$ for $\mathrm{Gd}_{1}-\mathrm{O}_{3}-\mathrm{N}_{5}-\mathrm{C}_{18}, 95.6(1)^{\circ}$ for $\mathrm{Gd}_{2}-\mathrm{O}_{6}-\mathrm{N}_{12}-\mathrm{C}_{27}$, and 168.1(2) for $\mathrm{Gd}_{2}-\mathrm{O}_{7}-\mathrm{N}_{14}-\mathrm{C}_{40}$. The local symmetry of the $\mathrm{Gd}$ atom coordination sphere is best described by a distorted triangular dodecahedron $\left(D_{2 \mathrm{~d}}\right)$, analysis with SHAPE 
software $^{38,39}$ giving CShM (continuous shape measurement) values of 0.36 and 0.61 (Table S4).

The $\mathrm{Cu}^{\mathrm{II}}$ ion sits in an elongated octahedral polyhedron. The axial positions are occupied by $\mathrm{N}$ atoms from two pyrazole groups $(\mathrm{Cu}-\mathrm{N}, 2.320(9)-2.396(1) \AA$, to be compared with 2.432(5) $\AA$ in $\left.\left[\mathrm{Gd}_{2} \mathrm{Cu}_{3}(\mathrm{hfac})_{12}(4-\mathrm{NIT}-\mathrm{MePyz})_{4}\right] .{ }^{34}\right)$, and four O atoms of two hfac coligands ( $\mathrm{Cu}-\mathrm{O}, 1.936(8)-2.001(8) \AA)$ are located in equatorial positions. The elongated $\mathrm{Cu}-\mathrm{N}$ bond in the axial direction is mainly due to Jahn-Teller effect. ${ }^{40}$ Each 4-NIT-MePyz ligand is coordinated to one $\mathrm{Cu}^{\mathrm{II}}$ and one $\mathrm{Ln}^{\mathrm{III}}$ ion by means of its pyrazole $\mathrm{N}$ and NO group, respectively. This assemblage scheme results in a 1-D coordination polymer with alternating metal centers bridged by 4-NIT-MePyz. The intrachain $\mathrm{Gd}^{\mathrm{III}}-\mathrm{Cu}^{\mathrm{II}}$ distances are 8.026(1) $\AA$, 8.543(1) $\AA$ and 8.380(1) $\AA$, respectively. Figure 2 shows the crystal packing diagram of 1 with relevant shortest interchain distances between paramagnetic centers, the values for 1-3 are gathered in Table 2.

Table 2. The shortest interchain distances $[\AA]$ for $\mathbf{1 - 3}$.

\begin{tabular}{lccc}
\hline Complex & $\mathbf{1 ~ G d}$ & $\mathbf{2}$ Tb & 3 Dy \\
\hline $\mathrm{Ln}-\mathrm{Ln}$ & $13.263(1)$ & $13.505(1)$ & $13.290(6)$ \\
$\mathrm{Ln}-\mathrm{Cu}$ & $11.855(2)$ & $12.676(1)$ & $11.589(3)$ \\
$\mathrm{Cu}-\mathrm{Cu}$ & $12.879(2)$ & $12.830(1)$ & $12.873(6)$ \\
$\mathrm{Rad}-\mathrm{Rad}$ & $4.06(1)$ & $4.023(9)$ & $4.07(1)$ \\
\hline
\end{tabular}

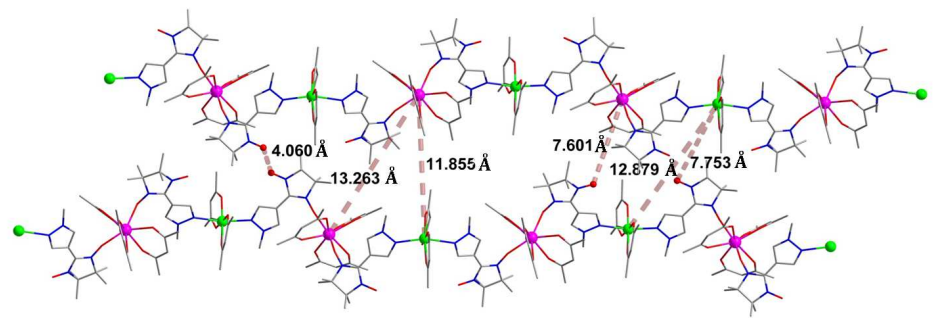

Figure 2. Crystal packing diagram of complex 1. H and F atoms are not shown for the sake of clarity. 


\section{Magnetic Properties}

The temperature dependences of the molar magnetic susceptibility, $\chi_{M}$ (given for a $\operatorname{LnCuRad}_{2}$ moiety), for 1-3 are plotted as $\chi_{\mathrm{M}} T$ versus $T$ in Figures 3 and 4 , and Fig. S10, respectively.

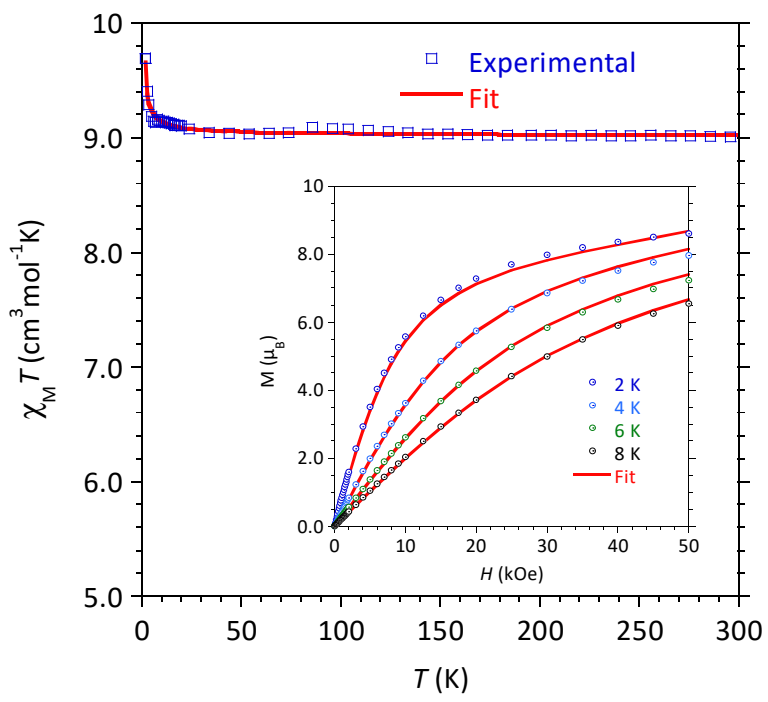

Figure 3. Magnetic behavior for Gd derivative 1: $\chi_{\mathrm{M}} T$ versus $T$ and (insert) $M$ versus $H$, the red lines are the best-fits obtained with the parameters discussed in the text.

At $300 \mathrm{~K}$, the $\chi_{\mathrm{M}} T$ value of $\mathbf{1}$ is $8.95 \mathrm{~cm}^{3} \mathrm{~mol}^{-1} \mathrm{~K}$, which is close to the value of 9.04 $\mathrm{cm}^{3} \mathrm{~mol}^{-1} \mathrm{~K}$ expected for one $\mathrm{Gd}^{\mathrm{III}}$ ion $\left({ }^{8} \mathrm{~S}_{7 / 2}, S=7 / 2, L=0, C=7.88 \mathrm{~cm}^{3} \mathrm{Kmol}^{-1}\right)$, one $\mathrm{Cu}^{\mathrm{II}}$ ions $\left(S=1 / 2, C=0.41 \mathrm{~cm}^{3} \mathrm{Kmol}^{-1}, \mathrm{~g}=2.10\right)$, and two organic radicals $(S=1 / 2, C$ $=0.375 \mathrm{~cm}^{3} \mathrm{Kmol}^{-1}$ ) in the absence of exchange interactions. As the temperature is decreased, the value of $\chi_{\mathrm{M}} T$ remains constant until $15 \mathrm{~K}$ and below this temperature, it increases to reach $9.75 \mathrm{~cm}^{3} \mathrm{Kmol}^{-1}$ at $2 \mathrm{~K}$. Such a behavior is in agreement with the ferromagnetic Gd-NIT interactions anticipated in this system. Field-dependent magnetization for 1 (Fig. 4) indicate a magnetization of $8.75 \mu_{\mathrm{B}}$ for $50 \mathrm{kOe}$ at $2 \mathrm{~K}$, a value between the $10 \mu_{\mathrm{B}}$ anticipated for ferromagnetic Gd-Radical interactions and the $6 \mu_{\mathrm{B}}$ that would result from antiferromagnetic Gd-Rad interactions, in addition to the contribution of a paramagnetic $\mathrm{Cu}^{\mathrm{II}}$ center.

For this spin chain, three exchange pathways can be anticipated, namely the exchange interactions between the $\mathrm{Gd}^{\mathrm{III}}$ ion and the coordinated NIT radicals $\left(J_{1}\right)$, a next-neighbor interaction between two NIT units via the $\operatorname{Gd}^{\mathrm{III}}$ ion $\left(J_{2}\right)$, and a 
$\mathrm{Cu}^{\mathrm{II}}$-nitroxide interaction via the pyrazole ring that is expected to be weak due to the axial coordinated $\mathrm{N}$ atom. The magnetic data of $\mathbf{1}$ have been modeled as a trispin unit of NIT-Gd-NIT with $J_{1}$ and $J_{2}$ exchange parameters (corresponding Hamiltonian: $\left.\hat{H}=-J_{1}\left(\hat{S}_{G d} \cdot \hat{S}_{\text {Rad } 1}+\hat{S}_{G d} \cdot \hat{S}_{\text {Rad } 2}\right)-J_{2} \hat{S}_{\text {Rad } 1} \cdot \hat{S}_{\text {Rad } 2}\right)$, plus one independent $\mathrm{Cu}{ }^{\mathrm{II}}$ ion. The molecular meanfield approximation ( $\left.z J^{\prime}\right)$ was introduced to account both for the weak magnetic exchange between the $\mathrm{Cu}(\mathrm{II})$ and the radicals moieties via the pyrazole rings, and possible interchain interactions.. The $\chi_{M} T$ and magnetization data were simultaneously analyzed using $P H I$ program. $^{41}$ A very good agreement between experimental and calculated behaviors (Fig. 4) was obtained for , $J_{1}=0.8 \pm 0.7 \mathrm{~cm}^{-1}$, $J_{2}=-4.7 \pm 0.2 \mathrm{~cm}^{-1}, z J^{\prime}=(17.0 \pm 0.4) \times 10^{-3} \mathrm{~cm}^{-1}$, and $g=2.05 \pm 0.01$. The $J_{1}$ value confirms the anticipated ferromagnetic Gd ${ }^{\mathrm{III}}-\mathrm{NIT}$ interactions, which has been attributed to an electron transfer from the $\pi^{*}$ orbital of the radical to $6 \mathrm{~s} / 6 \mathrm{p}$ empty orbitals of $\mathrm{Gd}^{\mathrm{III}}$ ion. ${ }^{42,43}$ The strength of the antiferromagnetic next-neighbor interaction between the coordinated radicals, $J_{2}$, conform values reported for related species. ${ }^{44-46}$ This antiferromagnetic contribution is at the origin of the intermediate magnetization values observed in the $M$ versus $H$ behaviors for $\mathbf{1}$. Finally, it is advisable to consider the value of $z J$ ' with precaution, because a perfect fit could be obtained even without this parameter, $J_{l}$ being sufficient to model the increase de $\chi_{M} T$ at low $T$. Therefore, the $\chi_{\mathrm{M}} T$ behavior for $\mathbf{1}$ does not allow to conclude about on a spin-chain behavior, but any ambiguity is removed with the $\mathrm{Tb}$ and $\mathrm{Dy}$ derivatives.

For complexes 2 and 3, the $\chi_{\mathrm{M}} T$ values at $300 \mathrm{~K}$ are 12.94 and $15.20 \mathrm{~cm}^{3} \mathrm{Kmol}^{-1}$, respectively, close to the estimated values $\left(12.98 \mathrm{~cm}^{3} \mathrm{Kmol}^{-1}\right.$ for 2 and 15.33 $\mathrm{cm}^{3} \mathrm{Kmol}^{-1}$ for 3) for an isolated system composed of one $\mathrm{Ln}^{\mathrm{III}}$ ion $\left(\mathrm{Tb}^{\amalg}:{ }^{7} \mathrm{~F}_{6}, S=3\right.$, $L=3, C=11.82 \mathrm{~cm}^{3} \mathrm{Kmol}^{-1}$; Dy ${ }^{\amalg}:{ }^{6} \mathrm{H}_{15 / 2}, S=5 / 2, L=5, C=14.17 \mathrm{~cm}^{3} \mathrm{Kmol}^{-1}$ ), one $\mathrm{Cu}^{\mathrm{II}}$ ion and two radicals. With cooling, $\chi_{\mathrm{M}} T$ smoothly decreases until $25 \mathrm{~K}$ as a result of the crystal field effect, ${ }^{47}$ and below this temperature, a steep increase is observed to reach a sharp maximum of $91.1 \mathrm{~cm}^{3} \mathrm{Kmol}^{-1}$ for 2 and $61.5 \mathrm{~cm}^{3} \mathrm{Kmol}^{-1}$ for 3 at $5 \mathrm{~K}$, followed by a linear decrease for lower $T$ to respectively $45 \mathrm{~cm}^{3} \mathrm{Kmol}^{-1}$ and 46.2 $\mathrm{cm}^{3} \mathrm{Kmol}^{-1}$ at $2 \mathrm{~K}$. Such a feature at low $T$ suggested saturation of the magnetization that was confirmed by the behavior obtained with a smaller applied field (50 Oe) plotted in black in Fig. 5. In these conditions, the maximum for $\chi_{M} T$ is found at 234 
$\mathrm{cm}^{3} \mathrm{Kmol}^{-1}$ for $4 \mathrm{~K}$, a temperature below which $\chi_{\mathrm{M}}$ tends to saturate (Fig. 5, insert). This behavior precludes any significant contribution from antiferromagnetic interactions between the chains. The observation for $\mathbf{2}$ and $\mathbf{3}$ of the divergence of $\chi_{\mathrm{M}} T$ at low temperature that is not seen above $2 \mathrm{~K}$ for $\mathbf{1}$ might be related to the large Ln-radical exchange interaction for $\mathrm{Tb}$ and $\mathrm{Dy}$ as compared to $\mathrm{Gd}{ }^{48}$ that will contribute to strengthen the exchange interaction with $\mathrm{Cu}$ and, in turn, favor correlation growth along the chain for higher temperature. The field dependences of the magnetization for $\mathbf{2}$ and $\mathbf{3}$ at $2 \mathrm{~K}$ are characterized by a very steep increase to ca $4.5 \mu_{\mathrm{B}}$ for small fields $(<1 \mathrm{kOe})$, followed by a much smoother augmentation to reach respectively, 5.9 and $6.6 \mu_{\mathrm{B}}$ for $H_{\mathrm{DC}}=50 \mathrm{kOe}$ (Fig. S11). These magnetic behaviors for $\mathbf{2}$ and $\mathbf{3}$ are signatures for short-range correlation as expected for 1-D spin arrays or for ferromagnetic 3D order that is however, excluded by $\mathrm{AC}$ susceptibility studies (vide infra).

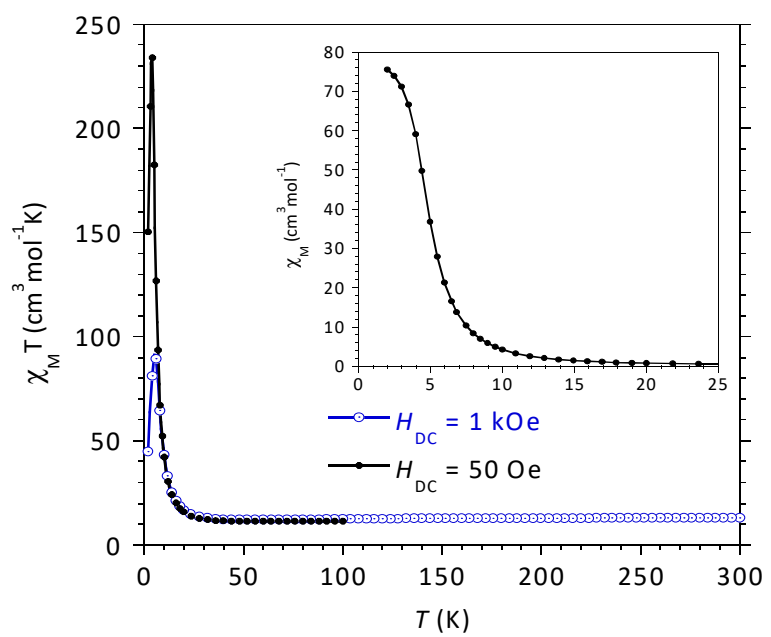

Figure 4. $\chi_{\mathrm{M}} T$ versus $T$ for 2 with $H_{\mathrm{DC}}=1 \mathrm{kOe}$ and 50 Oe blue and black, respectively; (insert) detail of the variation of $\chi_{\mathrm{M}}$ at low $T$ (50 Oe field).

For Ising or anisotropic Heisenberg spin chains, with lowering temperature, the magnetic susceptibility is predicted to exhibit an exponential dependence in zero field following the expression $\chi_{\mathrm{M}} T=C_{\text {eff }} \exp \left[\Delta_{\xi} /\left(k_{\mathrm{B}} T\right)\right]$, where $\Delta_{\xi}$ is the energy required to create a domain wall in the chain, $C_{\text {eff }}$ represents the effective Curie constant. ${ }^{49,50}$ For complexes 2 and 3, a linear region, respectively between 8-23 K and 5-15 K (Fig. S12) is found in the plots of $\ln \left(\chi_{M}{ }^{\prime} T\right)$ versus $1 / T$, where $\chi_{M}^{\prime}$ is the in-phase susceptibility 
measured with an AC field of 3 Oe with $v=100 \mathrm{~Hz}$ without applied DC field. The analyses of these linear parts gave for $2 \Delta_{\xi} / k_{\mathrm{B}}=19.4 \mathrm{~K}, C_{\text {eff }}=6.4 \mathrm{~cm}^{3} \mathrm{~mol}^{-1} \mathrm{~K}$, and for $3 \Delta_{\xi} / k_{\mathrm{B}}=9.1 \mathrm{~K}, C_{\text {eff }}=8.77 \mathrm{~cm}^{3} \mathrm{~mol}^{-1} \mathrm{~K}$.

(a)

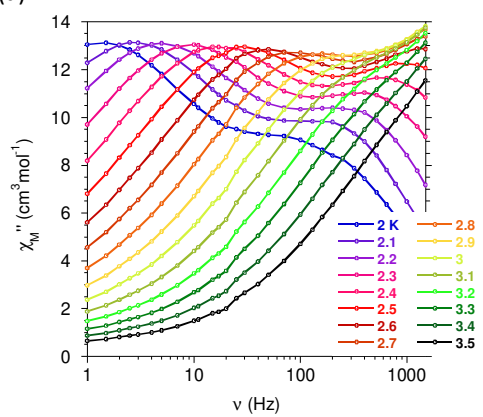

(b)

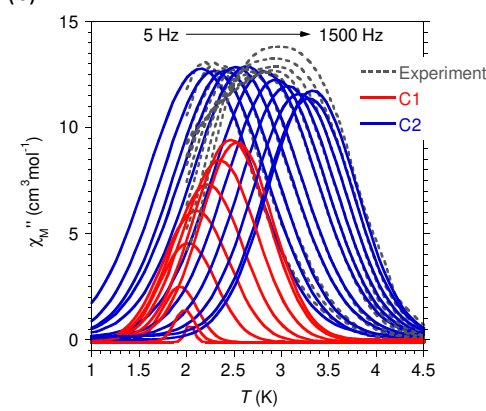

(c)

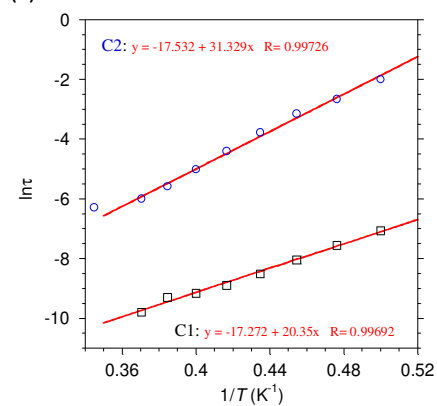

Figure 5. (a) Frequency dependence of $\chi_{\mathrm{M}}$ " (in zero field) in the temperature range of 2-3.5 K, (b) temperature dependence of the two contributions ( $\mathrm{C} 1$ and $\mathrm{C} 2)$ obtained by deconvolution of the experimental $\chi_{\mathrm{M}}$ " versus $T$ behavior (dashed lines), (c) temperature dependence of the relaxation time, $\tau$, for the two contributions in $\mathbf{2}$.

For chain 2, AC susceptibility showed temperature dependent in-phase $\left(\chi^{\prime}\right)$ and out-of-phase $\left(\chi^{\prime \prime}\right)$ signals in zero field below $5 \mathrm{~K}$ (Fig. S13). For the higher frequencies $(v>500 \mathrm{~Hz})$ the $\chi_{\mathrm{M}}$ " versus $T$ behavior appears rather broad and becomes dissymmetric for lower frequencies before showing the usual sharper temperature dependency. Such broad and dissymmetric behavior suggested the presence of two independent but close contributions. These two relaxations are clearly revealed by the plot of $\chi_{M}$ " versus $v$ for temperatures between 2 and $3.5 \mathrm{~K}$ (Fig. 5a) showing two maxima clearly visible in the high and low frequency domain, both being shifted to higher frequencies with temperature. The deconvolution of the $\chi_{\mathrm{M}}$ " versus $T$ curves in two components of Gaussian distribution allowed to visualize the two independent contributions (Fig. 5b and S14). One of these contributions, labeled hereafter $\mathrm{C} 1$, rapidly decreases as $\mathrm{AC}$ frequencies become slower and vanishes below $40 \mathrm{~Hz}$. Moreover, the temperature of the maximum of $\mathrm{C} 1$ is little shifted with $\mathrm{v}$. The second component, C2, remain of same intensity over the whole frequency range (5 to 1500 $\mathrm{Hz}$ ) and its maximum moves from 2.1 to $3.3 \mathrm{~K}$ between the lowest and the highest 
frequency. The behavior of C2 is similar to that usually observed for an SCM. ${ }^{51,52}$ The origin of $\mathrm{C} 1$ is more puzzling and likely related to inter-chain interactions; ${ }^{53}$ but ferromagnetic ordering can be ruled out because of the shift of the $\chi_{M}$ ' and $\chi_{M}$ " signals with temperature, and of the decreasing $\chi_{M}{ }^{\prime \prime}$ signal with frequency. Finally, when AC data were recorded with an applied DC field of $1 \mathrm{kOe}$, only the maximum for $\chi_{\mathrm{M}}$ " versus $v$ in the higher frequency domain (i.e. C1) remained but much reduced in intensity (Fig. S15). The quenching by an applied field of the relaxation of $\mathrm{C} 2$ is a further support to a SCM behavior.

The relaxation times $(\tau)$ for both contributions $\mathrm{C} 1$ and $\mathrm{C} 2$ were deduced from $\chi_{\mathrm{M}}$ " versus $v$ behaviors using an expression composed by two generalized Debye model to account for each relaxation process (Fig. S16). The linear variation of $\ln \tau$ versus $1 / T$ (Fig. 5c) were fitted by Arrhenius expression $\tau=\tau_{0} \exp \left(\Delta_{\tau} / k_{\mathrm{B}} T\right)$, leading to the energy barrier $\Delta_{\tau} / k_{\mathrm{B}}=31.3 \mathrm{~K}$ and pre-exponential factor $\tau_{0}=2.4 \times 10^{-8} \mathrm{~s}$ for the relaxation attributed to the SCM 2, and $\Delta_{\tau} / k_{\mathrm{B}}=20.3 \mathrm{~K}$ and $\tau_{0}=3.1 \times 10^{-8} \mathrm{~s}$ for the relaxation observed only in the higher frequency range (i.e. $\mathrm{C} 1$ in Fig. 5b). For the $\mathrm{AC}$ data obtained with applied DC field, the temperature dependence of $\tau$ lead to $\Delta_{\tau} / k_{\mathrm{B}}=20.5$ $\mathrm{K}$ and $\tau_{0}=1.7 \times 10^{-10} \mathrm{~s}$, in agreement with the energy barrier estimated for $\mathrm{C} 1$ in zero field. Additionally, the values of $\Delta_{\tau} / k_{\mathrm{B}}$ and $\tau_{0}$ obtained from $\mathrm{C} 1$ and $\mathrm{C} 2$ components derived from the deconvolution of the experimental $\chi_{M}$ " versus $T$ curves are $21 \mathrm{~K}$ and $3 \times 10^{-8} \mathrm{~s}$ for $\mathrm{C} 1,33.4 \mathrm{~K}$ and $6.8 \times 10^{-9} \mathrm{~s}$ for $\mathrm{C} 2$ (Fig. S17), which are in line with those obtained above. The Cole-Cole plots for temperatures between 2.0 and $3.0 \mathrm{~K}$ show two contributions, illustrating two concomitent magnetic relaxation processes. The distribution widths of the relaxation times, $\alpha$, obtained are ranging from 0.12 to 0.33 for $\mathrm{C} 1$ and 0.41 to 0.51 for the SCM (C2). Complex 3 showed just the onset of an out-of-phase $\left(\chi^{\prime \prime}\right)$ signal below $3 \mathrm{~K}$ even in dc field (Fig. S19).

It is reasonable to assume that the relaxation mode for SCM 2 is governed by a finite-size regime due to inevitable chemical defects limiting the actual lengths of the chains. In such a situation, the energy barrier for demagnetization results from the 
contributions of the correlation energy and of the blocking energy due to the magnetic anisotropy of the repeating unit, i.e. $\Delta_{\tau}=\Delta_{\xi}+\Delta_{\text {aniso. }}{ }^{54}$ For 2 , we find $\Delta_{\text {aniso }} / k_{\mathrm{B}}=12 \mathrm{~K}$. This value compares very well with the anisotropy barrier of $13 \mathrm{~K}$ reported for a $\left[\mathrm{Cu}_{3} \mathrm{~Tb}_{2}(4-\mathrm{NIT}-\mathrm{MePyz})_{4}\right] \mathrm{SMM}$ that can be considered, disregarding a terminal $\mathrm{Cu}$ ion, as the elementary unit of SCM $2 .^{34}$

\section{Conclusion}

Radical-Cu-Ln SCMs are scarce and among them very few involve $\mathrm{Tb}^{\mathrm{III}}$. A new example was obtained in this family of hetero-tri-spin chains using the 4-NIT-MePyz radical as bridge between the $\mathrm{Cu}^{\mathrm{II}}$ and $\mathrm{Ln}^{\mathrm{III}}$ ions. The energy barrier $\Delta_{\tau} / k_{\mathrm{B}}$ for $\mathbf{2}$ is the highest so far reported for this type of $2 \mathrm{p}-3 \mathrm{~d}-\mathrm{Tb}$ SCMs. ${ }^{46,51}$ An interestingly feature for this material are the two contributions to the AC susceptibility observed in the

same temperature range. SCM behavior concomitant to an antiferromagnetic ${ }^{54,55}$ or ferromagnetic ${ }^{53}$ ordering is often found but this is clearly not the case for $\mathbf{2}$. In present case, both contributions are characterized by a slow relaxation of the magnetization, one clearly associated to a SCM while second remains to be understood. This work demonstrates the effect of inter and intra-chain magnetic exchanges on magnetic relaxation for 1D system and provides valuable information for designing SCMs.

\section{Supporting Information}

Tables of key bond lengths and angles, SHAPE analysis, crystal structures, packing diagrams, additional magnetic data and PXRD patterns.

\section{Conflicts of interest}

The authors declare no competing financial interest. 


\section{Acknowledgements}

This work was financially supported by the National Key R\&D Program of China (2018YFA0306002) and the National Natural Science Foundation of China (No. 21773122).

\section{References}

1 A. Caneschi, D. Gatteschi, P. Rey and R. Sessoli, Inorg. Chem., 1991, 30, 3936-3941.

2 D. Luneau, and P. Rey, Coord. Chem. Rev., 2005, 249, 2591-2611.

3 A. E. Thorarinsdottir and T. D. Harris, Chem Rev., 2020, 120, 8716-8789.

4 K. Inoue, T. Hayamizu, H. Iwamura, D. Hashizume and Y. Ohash, J. Am. Chem. Soc., 1996, 118, 1803-1804.

5 K. Fegy, D. Luneau, T. Ohm, C. Paulsen and P. Rey, Angew. Chem. Int.Ed., 1998, 37, $1270-1273$.

6 K. H. Stone, P. W. Stephens, A. C. McConnell, E. Shurdha, K. I. Pokhodnya and J. S. Miller, Adv Mater., 2010, 22, 2514-2519.

7 K. I. Pokhodnya, M. Bonner, J.H. Her, P. W. Stephens and J. S. Miller, J. Am. Chem. Soc., 2006, 128, 15592-15593.

8 W. Kosaka, Z. Liu, and H. Miyasaka, Dalton Trans., 2018, 47, 11760-11768.

9 W. Kosaka, M. Itoh, and H. Miyasaka, Mater. Chem. Front., 2018, 2, 497-504.

10 P. Perlepe, I. Oyarzabal, A. Mailman, M. Yquel, M. Platunov, I. Dovgaliuk, M. Rouzières, P. Négrier, D. Mondieig, E. A. Suturina, M-A. Dourges, S. Bonhommeau, R. A. Musgrave, K. S. Pedersen, D. Chernyshov, F. Wilhelm, A. Rogalev, C. Mathonière, and R. Clérac, Science, 2020, 370, 587.

11 S. Demir, I.-R. Jeon, J. R. Long, and T. D. Harris, Coord. Chem. Rev., 2015, 289-290, 149-176.

12 A. Caneschi, D. Gatteschi, N. Lalioti, C. Sangregorio, R. Sessoli, G. Venturi, A. 
Vindigni, A. Rettori, M. G. Pini, and M. A. Novak, Angew. Chem. Int. Ed., 2001, 40, 1760-1763.

13 J. D. Rinehart, M. Fang, W. J. Evans, and J. R. Long, Nat. Chem., 2011, 3, 538-42.

14 J. D. Rinehart, and J. R. Long, Chem. Sci., 2011, 2, 2078-2085.

15 D. N. Woodruff, R. E. Winpenny, and R. A. Layfield, Chem Rev., 2013, 113, $5110-5148$.

16 M. Urdampilleta, N. V. Nguyen, J. P. Cleuziou, S. Klyatskaya, M. Ruben, and W. Wernsdorfer, Int J Mol Sci., 2011, 12, 6656-6667.

17 L. Bogani, and W. Wernsdorfer, Nat Mater., 2008, 7, 179-186.

18 F. Troiani, and M. Affronte, Chem. Soc. Rev., 2011, 40, 3119-3129.

19 S. Demir, M. I. Gonzalez, L. E. Darago, W. J. Evans, and J. R. Long, Nat Commun., 2017, 8, 2144-2157.

20 M. G. F. Vaz and M. Andruh, Coord. Chem. Rev., 2021, 427, 213611-213634.

21 M. Zhu, L. Li, and J. P. Sutter, Inorg. Chem. Front., 2016, 3, 994-1003.

22 A. M. Madalan, H. W. Roesky, M. Andruh, M. Noltemeyer, and N. Stanica, Chem Commun (Camb)., 2002, 15, 1638-1639.

23 A. A. Patrascu, M. Briganti, S. Soriano, S. Calancea, R. A. Allao Cassaro, F. Totti, M. G. F. Vaz, and M. Andruh, Inorg Chem., 2019, 58, 13090-13101.

24 V. I. Ovcharenko, S. V. Fokin, G. V. Romanenko, V. N. Ikorskii, E. V. Tretyakov, S. F. Vasilevsky, and R. Z. Sagdeev, Mol. Phys., 2002, 100, 1107-1115.

25 M. V. Fedin, E. G. Bagryanskaya, H. Matsuoka, S. Yamauchi, S. L. Veber, K. Y. Maryunina, E. V. Tretyakov, V. I. Ovcharenko, and R. Z. Sagdeev, J Am Chem Soc., 2012, 134, 16319-16326.

26 M. Fedin, V. Ovcharenko, R. Sagdeev, E. Reijerse, W. Lubitz, and E. Bagryanskaya, Angew Chem Int Ed Engl., 2008, 47, 6897-6899.

27 S. L. Veber, M. V. Fedin, K. Y. Maryunina, A. Potapov, D. Goldfarb, E. Reijerse, W. Lubitz, R. Z. Sagdeev, V. I. Ovcharenko, and E. G. Bagryanskaya, Inorg Chem., 2011, 50, 10204-10212.

28 I. Y. Barskaya, S. L. Veber, S. V. Fokin, E. V. Tretyakov, E. G. Bagryanskaya, V. I. 
Ovcharenko, and M. V. Fedin, Dalton Trans., 2015, 44, 20883-20888.

29 V. Ovcharenko, S. Fokin, E. Chubakova, G. Romanenko, A. Bogomyakov, Z. Dobrokhotova, N. Lukzen, V. Morozov, M. Petrova, M. Petrova, E. Zueva, I. Rozentsveig, E. Rudyakova, G. Levkovskaya, and R. Sagdeev, Inorg Chem., 2016, 55, 5853-5861.

30 S. Fokin, V. Ovcharenko, G. Romanenko, and V. Ikorskii, Inorg. Chem., 2004, 43, 969-977.

31 O. Kahn, Molecular Magnetism; VCH: New York, 1993.

32 G. M. Sheldrick, SHELXS-2014, Program for structure solution; Universitat Gottingen: Gottingen, Germany, 2014.

33 G. M. Sheldrick, SHELXL-2014, Program for structure refinement; Universitat Gottingen, Gottingen, Germany, 2014.

34 J. Y. Shi, P. Y. Chen, M. Z. Wu, L. Tian, and Z. Y. Liu, Dalton Trans., 2019, 48, 9187-9193.

35 L. L. Li, S. Liu, Y. Zhang, W. Shi, and P. Cheng, Dalton Trans., 2015, 44, $6118-6125$.

36 P. Hu, Y.-Y. Gao, F.-P. Xiao, L.L Zhu, L.N. Wang, F. Su, and M. Zhang, Polyhedron, 2017, 130, 40-46.

37 C. Benelli, A. Caneschi, Dante Gatteschi, L. Pardi, and P. Rey, Inorg. Chem., 1989, 28, 275-280.

38 M. Llunell, D. Casanova, J. Cirera, P. Alemany, S. Alvarez, SHAPE 2.1; University of Barcelona: Barcelona, 2013.

39 D. Casanova, M. Llunell, P. Alemany, and S. Alvarez, Chem. - Eur. J., 2005, 11, 1479-1494.

40 Y. Ishimaru, M. Kitano, H. Kumada, N. Koga, and H. Iwamura, Inorg. Chem., 1998, 37, 2273-2280.

41 N. F. Chilton, R. P. Anderson, L. D. Turner, A. Soncini, and K. S. Murray, J. Comput. Chem., 2013, 34, 1164-1175.

42 M. Andruh, I. Ramade, E. Codjovi, O. Guillou, O. Kahn, and J. C. Trombe, J. Am. 
Chem. Soc., 1993, 115, 1822-1829.

43 T. Gupta, T. Rajeshkumar, and G. Rajaraman, Phys. Chem. Chem. Phys., 2014, 16, 14568-14577.

44 C. Benelli, A. Caneschi, D. Gatteschi, L. Pardi, P. Rey, D. P. Shum, and R. L. Carlin, Inorg. Chem., 1989, 28, 272-275.

45 J.P. Sutter, M. L. Kahn, S. Golhen, L. Ouahab, and O. Kahn, Chem. - Eur. J., 1998, $4(4), 571-576$.

46 M. Zhu, P. Hu, Y. Li, X. Wang, L. Li, D. Liao, V. M. Durga Prasad Goli, S. Ramasesha, and J. P. Sutter, Chem. - Eur. J., 2014, 20, 13356-13365.

47 M. L. Kahn, J.P. Sutter, S. Golhen, P. Guionneau, L. Ouahab, O. Kahn, and D. Chasseau, J. Am. Chem. Soc., 2000, 122, 3413-3421.

48 M. L. Kahn, R. Ballou, P. Porcher, O. Kahn, and J. P. Sutter, Chem. - Eur. J., 2002, 8, 525-531.

49 R. J. Glauber, J. Math. Phys., 1963, 4, 294-307.

50 C. Coulon, R. Clérac, L. Lecren, W. Wernsdorfer, and H. Miyasaka, Phys. Rev. B., 2004, 69, 132408.

51 J. Sun, J. Xie, L. Li, and J. P. Sutter, Inorg. Chem. Front., 2020, 7, 1949-1956.

52 K. Bretosh, V. Béreau, C. Duhayon, C. Pichon, and J. P. Sutter, Inorg. Chem. Front., 2020, 7, 1503-1511.

53 X. Liu, X. Feng, K. R. Meihaus, X. Meng, Y. Zhang, L. Li, J. Liu, K. S. Pedersen, L. Keller, W. Shi, Y. Zhang, P. Cheng, and Jeffrey R. Long, Angew. Chem., 2020, 132, $10697-10705$.

54 C. Coulon, V. Pianet, M. Urdampilleta, R. Clérac, In Molecular Nanomagnets and Related Phenomena; S. Gao, Ed; Springer Berlin Heidelberg: 2015; Vol. 164, p143-184.

55 C. Coulon, R. Clerac, W. Wernsdorfer, T. Colin, and H. Miyasaka, Phys Rev Lett, 2009, 102, 167204. 


\title{
Supporting Information
}

\section{Metal-radical hetero-tri-spin SCM with methyl-pyrazole-nitronyl nitroxide bridges}

\author{
Xiaohui Huang, ${ }^{1}$ Kang Wang, ${ }^{1}$ Jing Han, ${ }^{1}$ Junfang Xie, ${ }^{1}$ Licun $\mathrm{Li}^{* 1}$ and \\ Jean-Pascal Sutter ${ }^{* 2}$ \\ ${ }^{1}$ Department of Chemistry, Key Laboratory of Advanced Energy Materials Chemistry, \\ College of Chemistry, Nankai University, Tianjin 300071, China \\ ${ }^{2}$ Laboratoire de Chimie de Coordination du CNRS (LCC-CNRS), Université de \\ Toulouse, CNRS, Toulouse, France \\ * Corresponding author. E-mail address: \\ llicun@nankai.edu.cn \\ sutter@lcc-toulouse.fr
}

\section{Contents}

Table S1. Selected bond lengths $[\AA]$ and bond angles $\left[^{\circ}\right]$ for 1 ..................................... 3

Table S2. Selected bond lengths $[\AA]$ and bond angles $\left[^{\circ}\right]$ for 2 ..................................

Table S3. Selected bond lengths $[\AA]$ and bond angles $\left[{ }^{\circ}\right]$ for 3 ..................................... 3

Table S4. SHAPE analysis for the Ln coordination spheres for 1-3 ............................4

Figure S1. The coordination polyhedron of $\mathrm{Gd}^{\mathrm{III}}$ ion in 1 ..........................................4

Figure S2. The chain structure of complex 2.......................................................................5

Figure S3. The coordination polyhedron of $\mathrm{Tb}^{\mathrm{III}}$ ion in 2 ............................................5

Figure S4. The chain structure of complex 3.........................................................5

Figure S5. The coordination polyhedron of $\mathrm{Dy}^{\mathrm{III}}$ ion in 3..........................................6 6

Figure S6. Packing diagram of 1............................................................................................6 6

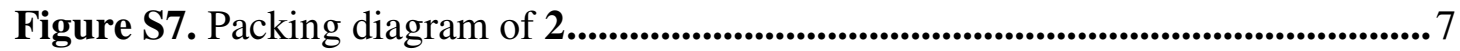

Figure S8. Packing diagram of 3.................................................................................................. 7

Figure S9. Powder X-ray diffraction patterns of complex 1-3. ....................................8

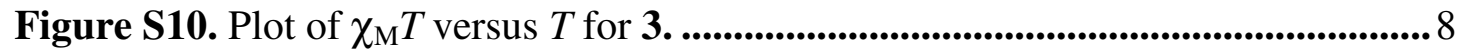

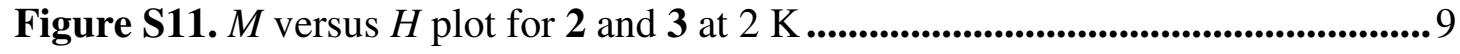


Figure S12. Plot of $\ln \left(\chi_{M}{ }^{\prime} T\right)$ versus $1 / T$ recorded in zero-field for (left) 2 and (right) 3; the solid red line is the best fit of the Glauber's expression to the linear part 8-23 K for 2 and $5-15 \mathrm{~K}$ for 3.. ................................................................................................

Figure S13. (left) Temperature of the AC susceptibility for $\mathbf{2}$ in the frequency range $1-1488 \mathrm{~Hz}$ in zero field for compound 2 ; (right) detail of the $\chi_{\mathrm{M}^{\prime \prime}}$ versus $T$ behavior..10

Figure S14. Selection of deconvolution of $\chi_{M^{\prime \prime}}$ versus $T\left(\mathrm{H}_{\mathrm{DC}}=0\right)$ for 2 for different frequencies. The dashed line is the fit of two Gaussian functions; $\mathrm{C} 1$ and $\mathrm{C} 2$ have been plotted with the best-fit parameters ................................................................................... 11

Figure S15. Temperature and Frequency dependence of $\chi_{\mathrm{M}}{ }^{\prime \prime}$ for 2 in $\mathrm{H}_{\mathrm{DC}}=1 \mathrm{kOe} . .11$

Figure S16. Experimental $\chi_{\mathrm{M}}{ }^{\prime}$ and $\chi_{\mathrm{M}}{ }^{\prime \prime}$ versus frequency for 2 (in zero field) with best fit (full red lines, for data from 2.0 to $2.8 \mathrm{~K}$ ) of an expression of two Debye models to account for the two relaxation processes. .................................................................11

Figure S17. $\ln \tau$ versus $1 / \mathrm{T}$ plots for compound 2 and best fit (solid lines) of the Arrhenius law. The $\tau$ values have been derived from the $T$ of the maximum of $\mathrm{C} 1$ and C2 components deconvoluted from experimental $\chi_{\mathrm{M}}{ }^{\prime \prime}$ versus $T$ behaviors. 12

Figure S18. Cole-Cole plots with best fits (full lines). The distribution widths of the relaxation times, $\alpha$, are large, ranging from 0.12 to 0.33 for $\mathrm{C} 1$ and 0.41 to 0.51 for the SCM (C2), likely resulting from the merging of the two data sets................12

Figure S19. Temperature-dependent ac signals of the $\chi_{M^{\prime}}$ and $\chi_{M}{ }^{\prime \prime}$ for compound $\mathbf{3}$ in (left) zero field and (right) $\mathrm{H}_{\mathrm{DC}}=1 \mathrm{kOe}$ field. 13 
Table S1. Selected bond distances $(\AA)$ and angles $\left(^{\circ}\right)$ for compound $\mathbf{1}$.

\begin{tabular}{llll}
\hline \multicolumn{4}{c}{$1 \mathrm{Gd}$} \\
\hline $\mathrm{Gd}(1)-\mathrm{O}(2)$ & $2.359(7)$ & $\mathrm{Gd}(1)-\mathrm{O}(3)$ & $2.322(7)$ \\
$\mathrm{Gd}(2)-\mathrm{O}(6)$ & $2.372(7)$ & $\mathrm{Gd}(2)-\mathrm{O}(7)$ & $2.299(7)$ \\
$\mathrm{N}(3)-\mathrm{O}(2)$ & $1.304(10)$ & $\mathrm{N}(5)-\mathrm{O}(3)$ & $1.294(10)$ \\
$\mathrm{Cu}(1)-\mathrm{N}(1)$ & $2.340(9)$ & $\mathrm{Cu}(1)-\mathrm{N}(16)$ & 2.489 \\
$\mathrm{Cu}(2)-\mathrm{N}(10)$ & $2.396(11)$ & $\mathrm{Cu}(2)-\mathrm{N}(7)$ & $2.320(9)$ \\
$\mathrm{N}(3)-\mathrm{O}(2)-\mathrm{Gd}(1)$ & $134.0(6)$ & $\mathrm{N}(5)-\mathrm{O}(3)-\mathrm{Gd}(1)$ & $148.6(6)$ \\
$\mathrm{N}(12)-\mathrm{O}(6)-\mathrm{Gd}(2)$ & $134.0(7)$ & $\mathrm{N}(14)-\mathrm{O}(7)-\mathrm{Gd}(2)$ & $164.0(6)$ \\
$\mathrm{O}(13)-\mathrm{Gd}(1)-\mathrm{O}(14)$ & $71.8(3)$ & $\mathrm{O}(16)-\mathrm{Gd}(1)-\mathrm{O}(15)$ & $72.5(2)$ \\
$\mathrm{O}(17)-\mathrm{Gd}(1)-\mathrm{O}(18)$ & $71.4(2)$ & $\mathrm{O}(24)-\mathrm{Gd}(2)-\mathrm{O}(23)$ & $72.6(3)$ \\
$\mathrm{O}(25)-\mathrm{Gd}(2)-\mathrm{O}(26)$ & $72.9(3)$ & $\mathrm{O}(27)-\mathrm{Gd}(2)-\mathrm{O}(28)$ & $71.6(3)$ \\
$\mathrm{O}(10)-\mathrm{Cu}(1)-\mathrm{O}(9)$ & $91.8(3)$ & $\mathrm{O}(12)-\mathrm{Cu}(1)-\mathrm{O}(11)$ & $92.6(3)$ \\
$\mathrm{O}(20)-\mathrm{Cu}(2)-\mathrm{O}(19)$ & $92.8(4)$ & $\mathrm{O}(22)-\mathrm{Cu}(2)-\mathrm{O}(21)$ & $91.9(3)$ \\
$\mathrm{Gd}(1)-\mathrm{O}(2)-\mathrm{N}(3)-\mathrm{C}(5)$ & $90.93(1)$ & $\mathrm{Gd}(1)-\mathrm{O}(2)-\mathrm{N}(5)-\mathrm{C}(18)$ & $-110.20(1)$ \\
$\mathrm{Gd}(2)-\mathrm{O}(6)-\mathrm{N}(12)-\mathrm{C}(27)$ & $95.62(1)$ & $\mathrm{Gd}(2)-\mathrm{O}(7)-\mathrm{N}(14)-\mathrm{C}(40)$ & $168.08(2)$ \\
\hline
\end{tabular}

Table S2. Selected bond distances $(\AA)$ and angles $\left(^{\circ}\right)$ for compound 2.

\begin{tabular}{llll}
\hline \multicolumn{3}{c}{$2 \mathrm{~Tb}$} \\
\hline $\mathrm{Tb}(1)-\mathrm{O}(2)$ & $2.301(4)$ & $\mathrm{Tb}(1)-\mathrm{O}(3)$ & $2.345(4)$ \\
$\mathrm{Tb}(2)-\mathrm{O}(6)$ & $2.288(5)$ & $\mathrm{Tb}(2)-\mathrm{O}(7)$ & $2.356(5)$ \\
$\mathrm{Cu}(1)-\mathrm{N}(1)$ & $2.293(5)$ & $\mathrm{Cu}(1)-\mathrm{N}(16)$ & $2.408(6)$ \\
$\mathrm{Cu}(2)-\mathrm{N}(10)$ & $2.488(5)$ & $\mathrm{Cu}(2)-\mathrm{N}(7)$ & $2.334(5)$ \\
$\mathrm{N}(3)-\mathrm{O}(2)-\mathrm{Tb}(1)$ & $147.8(4)$ & $\mathrm{N}(5)-\mathrm{O}(3)-\mathrm{Tb}(1)$ & $133.4(3)$ \\
$\mathrm{N}(12)-\mathrm{O}(6)-\mathrm{Tb}(2)$ & $165.8(4)$ & $\mathrm{N}(14)-\mathrm{O}(7)-\mathrm{Tb}(2)$ & $135.5(5)$ \\
$\mathrm{O}(14)-\mathrm{Tb}(1)-\mathrm{O}(13)$ & $72.05(15)$ & $\mathrm{O}(15)-\mathrm{Tb}(1)-\mathrm{O}(16)$ & $72.62(15)$ \\
$\mathrm{O}(18)-\mathrm{Tb}(1)-\mathrm{O}(17)$ & $72.35(15)$ & $\mathrm{O}(23)-\mathrm{Tb}(2)-\mathrm{O}(24)$ & $72.47(18)$ \\
$\mathrm{O}(25)-\mathrm{Tb}(2)-\mathrm{O}(26)$ & $71.91(17)$ & $\mathrm{O}(27)-\mathrm{Tb}(2)-\mathrm{O}(28)$ & $73.60(18)$ \\
$\mathrm{O}(10)-\mathrm{Cu}(1)-\mathrm{O}(9)$ & $91.9(2)$ & $\mathrm{O}(11)-\mathrm{Cu}(1)-\mathrm{O}(12)$ & $91.74(19)$ \\
$\mathrm{O}(20)-\mathrm{Cu}(2)-\mathrm{O}(19)$ & $91.50(18)$ & $\mathrm{O}(22)-\mathrm{Cu}(2)-\mathrm{O}(21)$ & $92.70(17)$ \\
\hline
\end{tabular}


Table S3. Selected bond distances $(\AA)$ and angles $\left({ }^{\circ}\right)$ for compound $\mathbf{3}$.

\begin{tabular}{llll}
\hline \multicolumn{3}{c}{$3 \mathrm{Dy}$} \\
\hline $\mathrm{Dy}(1)-\mathrm{O}(2)$ & $2.341(5)$ & $\mathrm{Dy}(1)-\mathrm{O}(3)$ & $2.297(6)$ \\
$\mathrm{Dy}(2)-\mathrm{O}(6)$ & $2.359(6)$ & $\mathrm{Dy}(2)-\mathrm{O}(7)$ & $2.285(5)$ \\
$\mathrm{Cu}(1)-\mathrm{N}(1)$ & $2.343(6)$ & $\mathrm{Cu}(1)-\mathrm{N}(16)$ & $2.496(6)$ \\
$\mathrm{Cu}(2)-\mathrm{N}(10)$ & $2.412(8)$ & $\mathrm{Cu}(2)-\mathrm{N}(7)$ & $2.315(7)$ \\
$\mathrm{N}(3)-\mathrm{O}(2)-\mathrm{Dy}(1)$ & $132.5(4)$ & $\mathrm{N}(5)-\mathrm{O}(3)-\mathrm{Dy}(1)$ & $148.3(5)$ \\
$\mathrm{N}(12)-\mathrm{O}(6)-\mathrm{Dy}(2)$ & $135.5(6)$ & $\mathrm{N}(14)-\mathrm{O}(7)-\mathrm{Dy}(2)$ & $165.0(5)$ \\
$\mathrm{O}(13)-\mathrm{Dy}(1)-\mathrm{O}(14)$ & $72.37(19)$ & $\mathrm{O}(16)-\mathrm{Dy}(1)-\mathrm{O}(15)$ & $73.3(2)$ \\
$\mathrm{O}(18)-\mathrm{Dy}(1)-\mathrm{O}(17)$ & $71.90(19)$ & $\mathrm{O}(24)-\mathrm{Dy}(2)-\mathrm{O}(23)$ & $72.5(2)$ \\
$\mathrm{O}(25)-\mathrm{Dy}(2)-\mathrm{O}(26)$ & $74.7(2)$ & $\mathrm{O}(27)-\mathrm{Dy}(2)-\mathrm{O}(28)$ & $72.0(2)$ \\
$\mathrm{O}(10)-\mathrm{Cu}(1)-\mathrm{O}(9)$ & $91.5(2)$ & $\mathrm{O}(11)-\mathrm{Cu}(1)-\mathrm{O}(12)$ & $93.1(2)$ \\
$\mathrm{O}(20)-\mathrm{Cu}(2)-\mathrm{O}(19)$ & $91.7(3)$ & $\mathrm{O}(21)-\mathrm{Cu}(2)-\mathrm{O}(22)$ & $91.6(2)$ \\
\hline
\end{tabular}

Table S4. SHAPE analysis for the Ln coordination spheres for 1-3.

\begin{tabular}{llllll}
\hline Compound & SAPR-8 & TDD-8 & JBTPR-8 & BTPR-8 & JSD-8 \\
\hline Gd1 & 2.207 & $\mathbf{0 . 3 6 2}$ & 2.174 & 1.685 & 2.527 \\
Gd2 & 1.879 & $\mathbf{0 . 6 0 6}$ & 1.891 & 1.464 & 2.998 \\
Tb1 & 2.268 & $\mathbf{0 . 3 5 4}$ & 2.163 & 1.721 & 2.459 \\
Tb2 & 1.800 & $\mathbf{0 . 5 2 7}$ & 1.953 & 1.524 & 3.030 \\
Dy1 & 2.340 & $\mathbf{0 . 3 4 3}$ & 2.196 & 1.754 & 2.459 \\
Dy2 & 1.887 & $\mathbf{0 . 5 4 0}$ & 1.998 & 1.598 & 3.019 \\
\hline
\end{tabular}

SAPR-8: Square antiprism; TDD-8: Triangular dodecahedron; JBTPR-8: Biaugmented trigonal prism J50; BTPR-8: Biaugmented trigonal prism; JSD-8: Snub diphenoid J84.
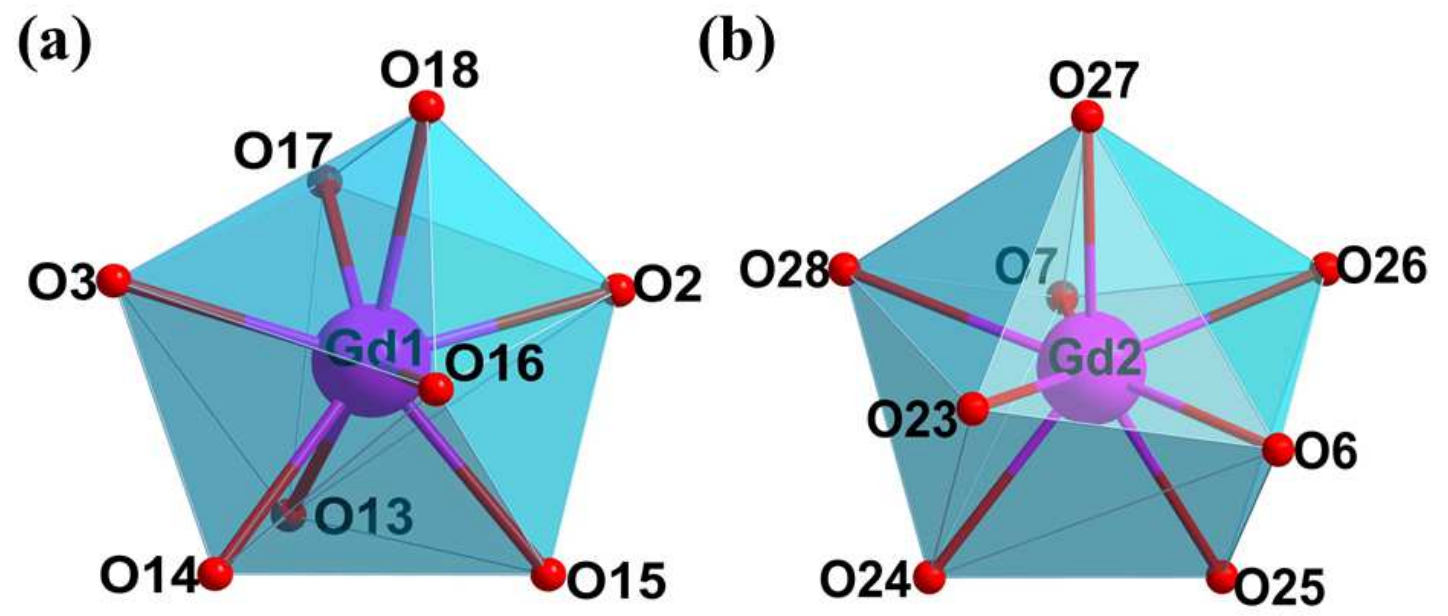

Fig. S1 The coordination polyhedron of $\mathrm{Gd}^{\mathrm{III}}$ ion in complex 1 (left) Gd1; (right) Gd2. 


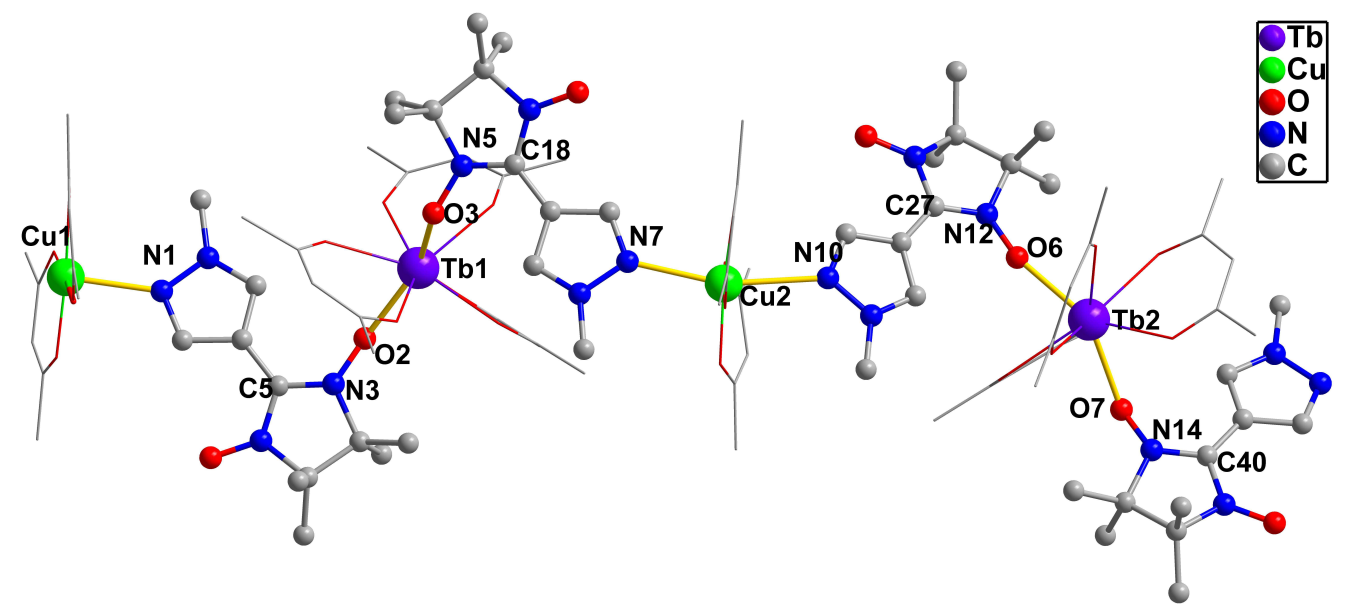

Fig. S2 The chain structure of complex 2. H and F atoms are not shown for the sake of clarity.
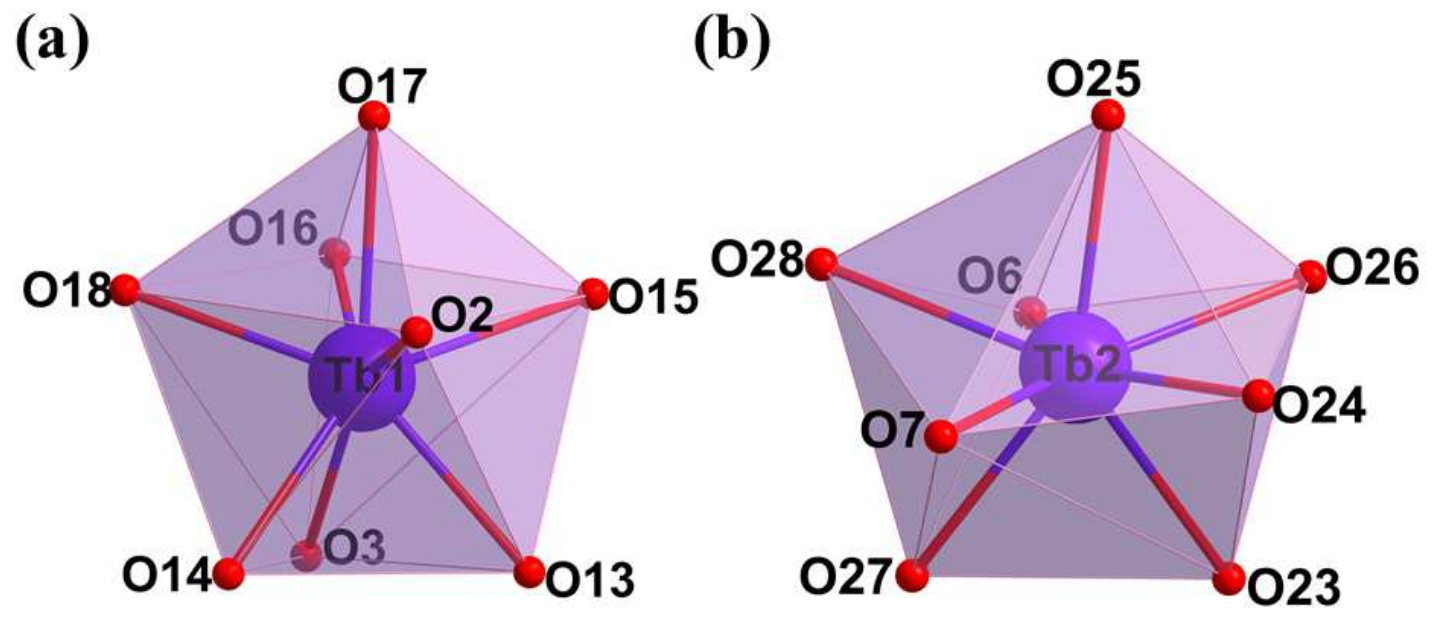

Fig. S3 The coordination polyhedron of $\mathrm{Tb}^{\mathrm{III}}$ ion in complex 2. (left) $\mathrm{Tb} 1$; (right) $\mathrm{Tb} 2$.

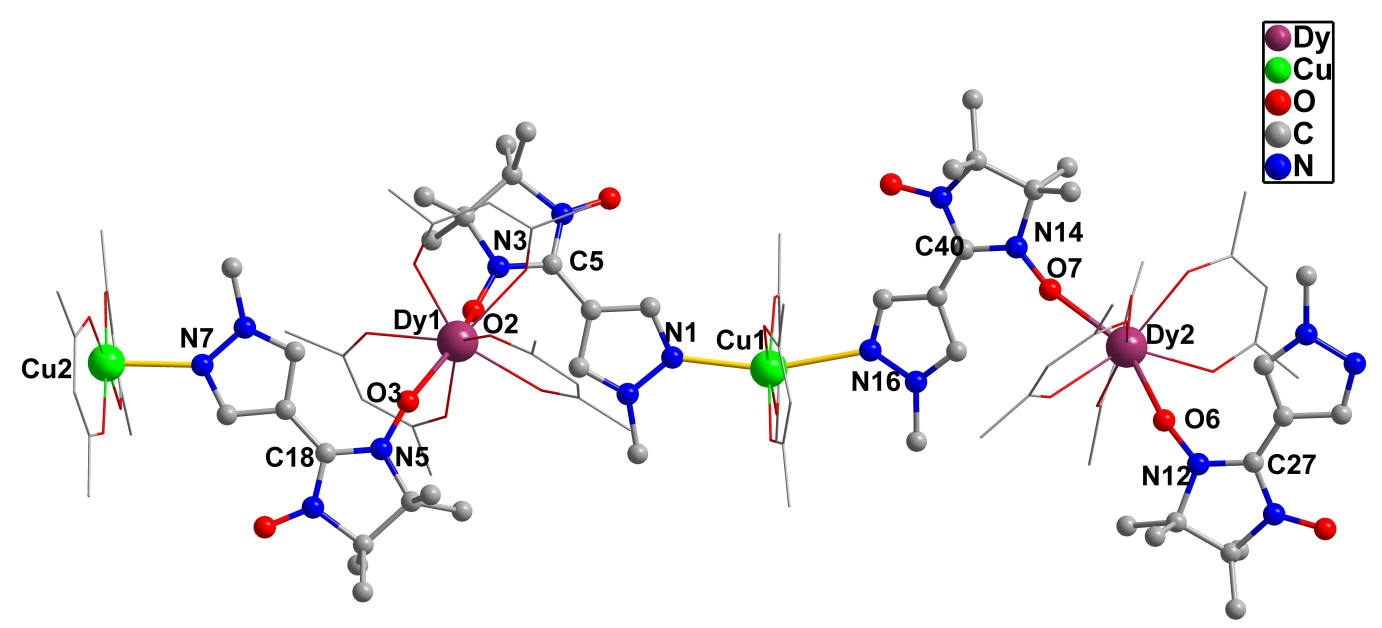

Fig. S4 The chain structure of complex 3. H and F atoms are not shown for the sake of clarity. 
(a)

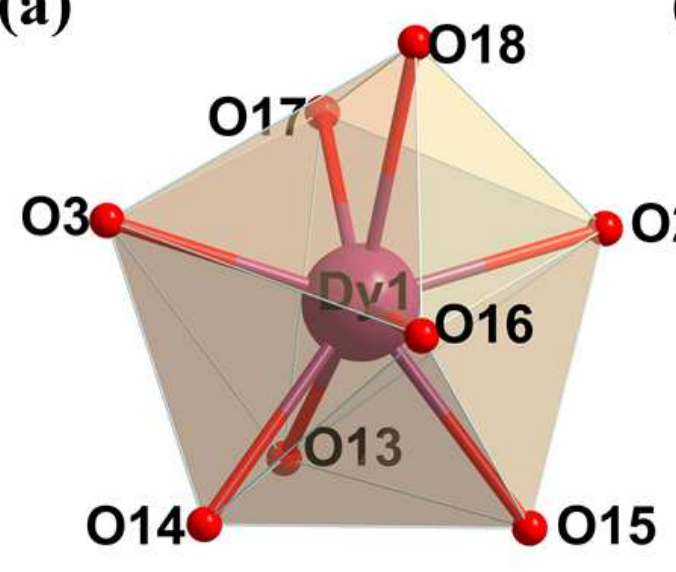

(b)

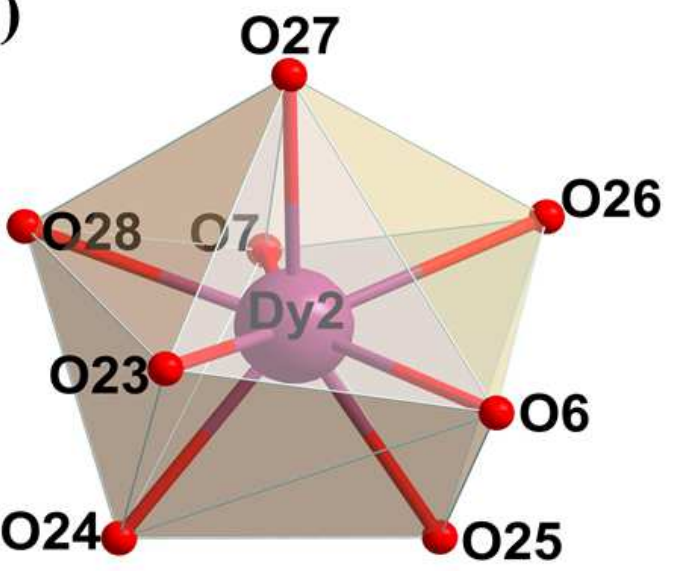

Fig. S5 The coordination polyhedron of Dy ${ }^{\mathrm{III}}$ ion in complex 3. (left) Dy1; (right) Dy2.

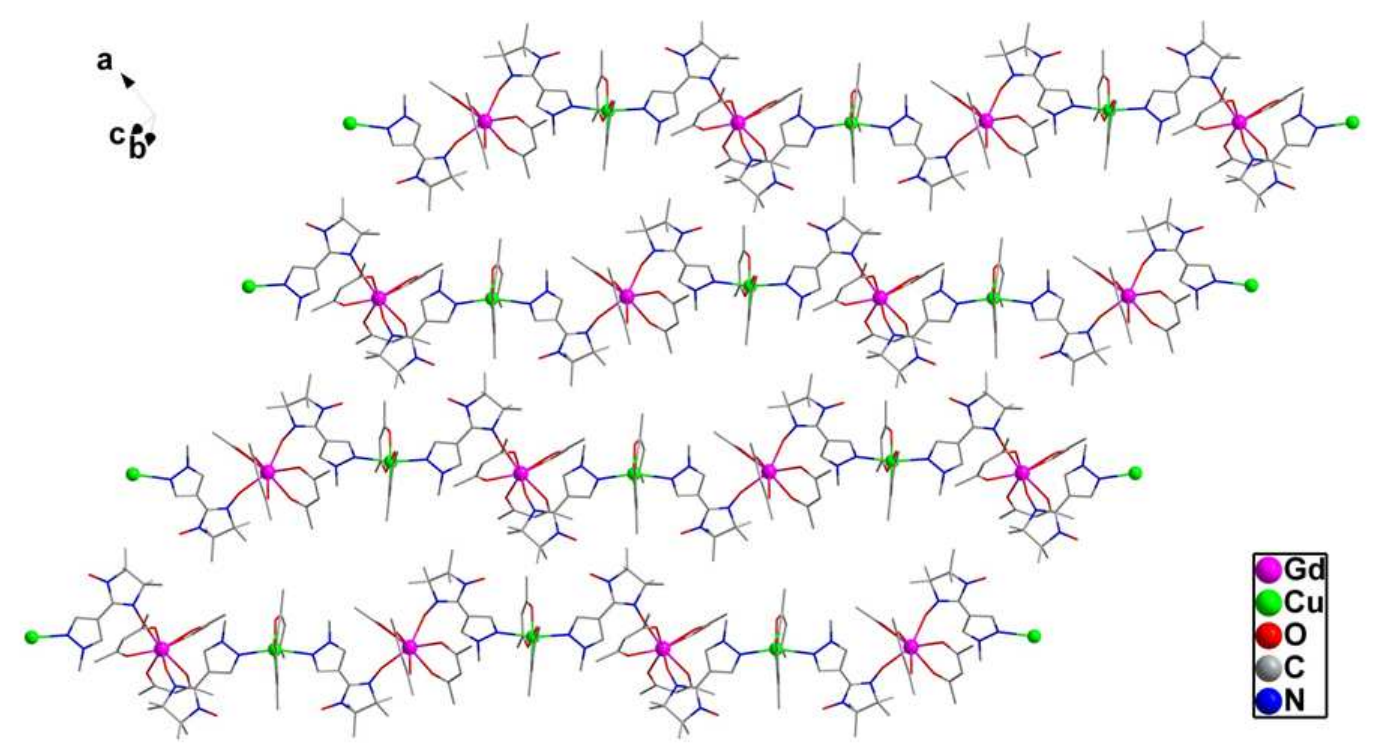

Fig. S6 Packing diagram of $\mathbf{1}$ ( $\mathrm{H}$ and $\mathrm{F}$ atoms are omitted for clarity). 


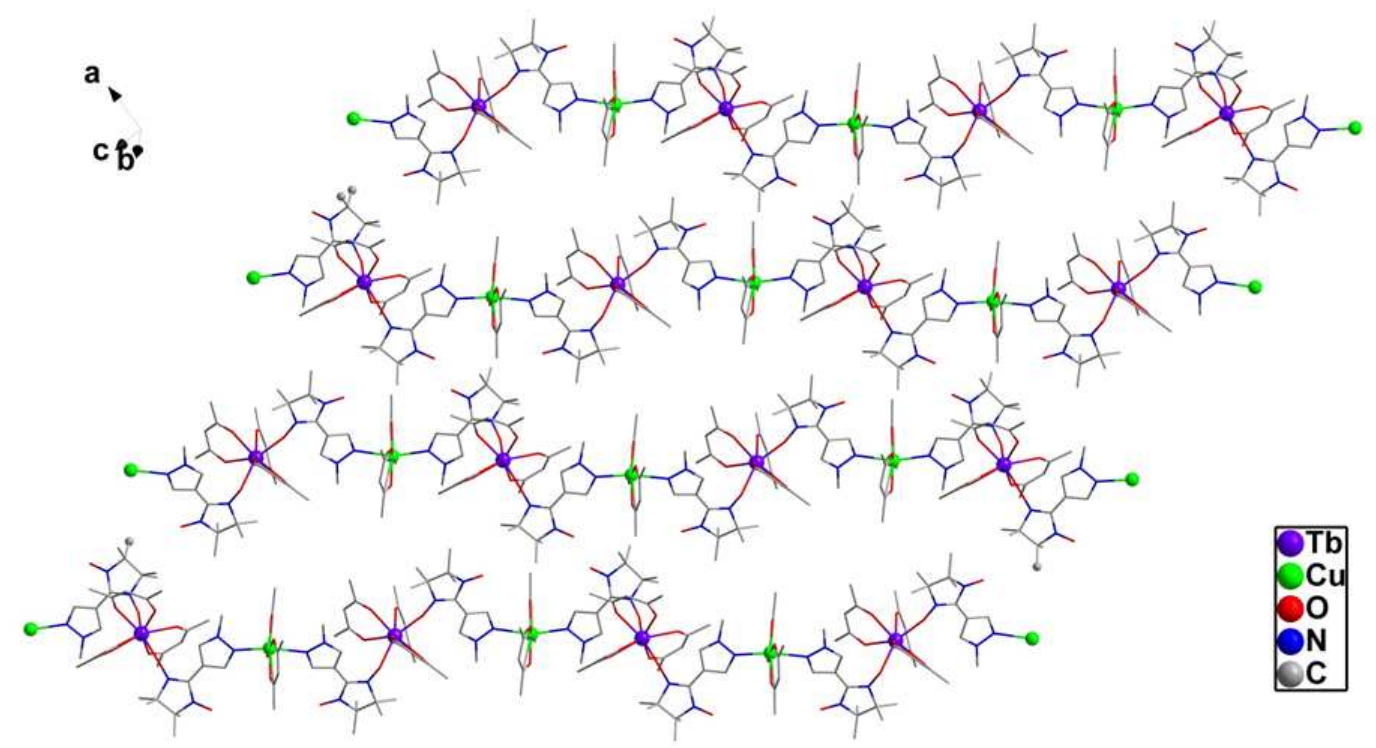

Fig. S7 Packing diagram of 2 ( $\mathrm{H}$ and $\mathrm{F}$ atoms are omitted for clarity).

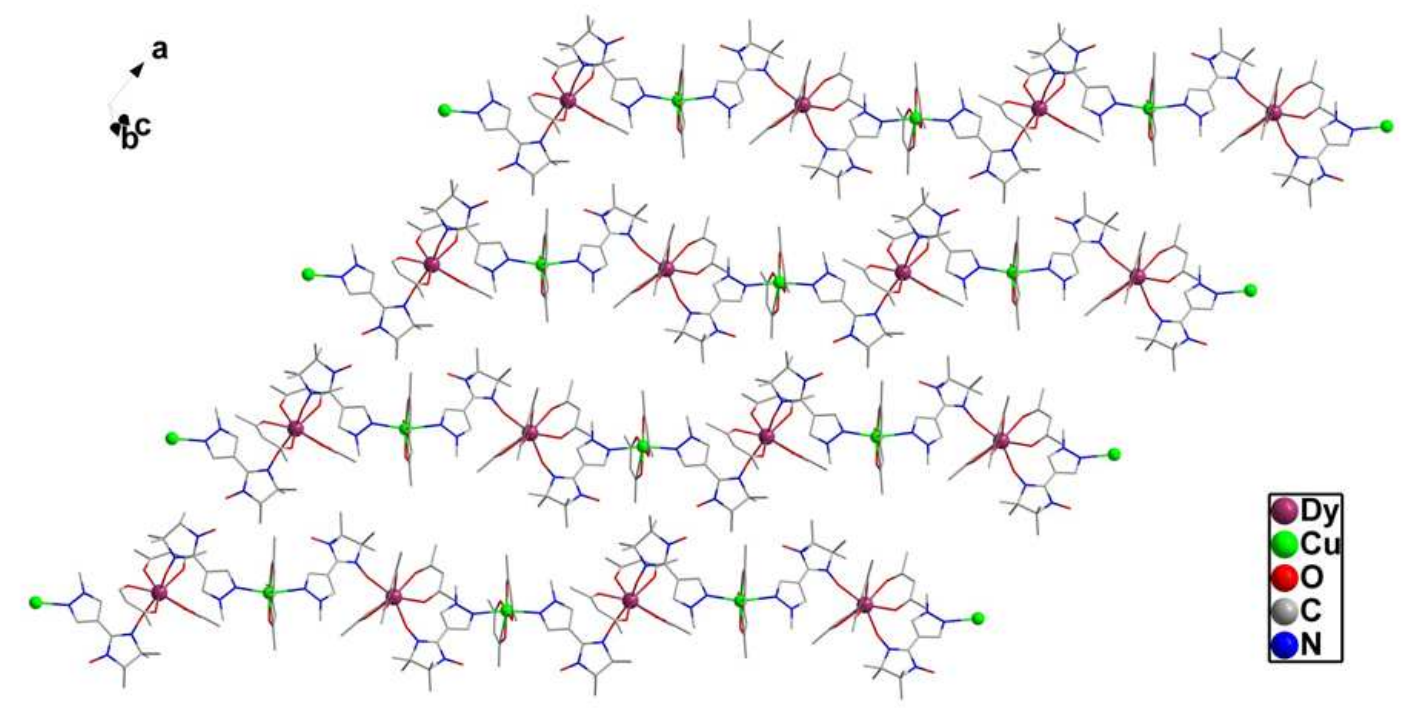

Fig. S8 Packing diagram of $\mathbf{3}$ (H and $\mathrm{F}$ atoms are omitted for clarity). 

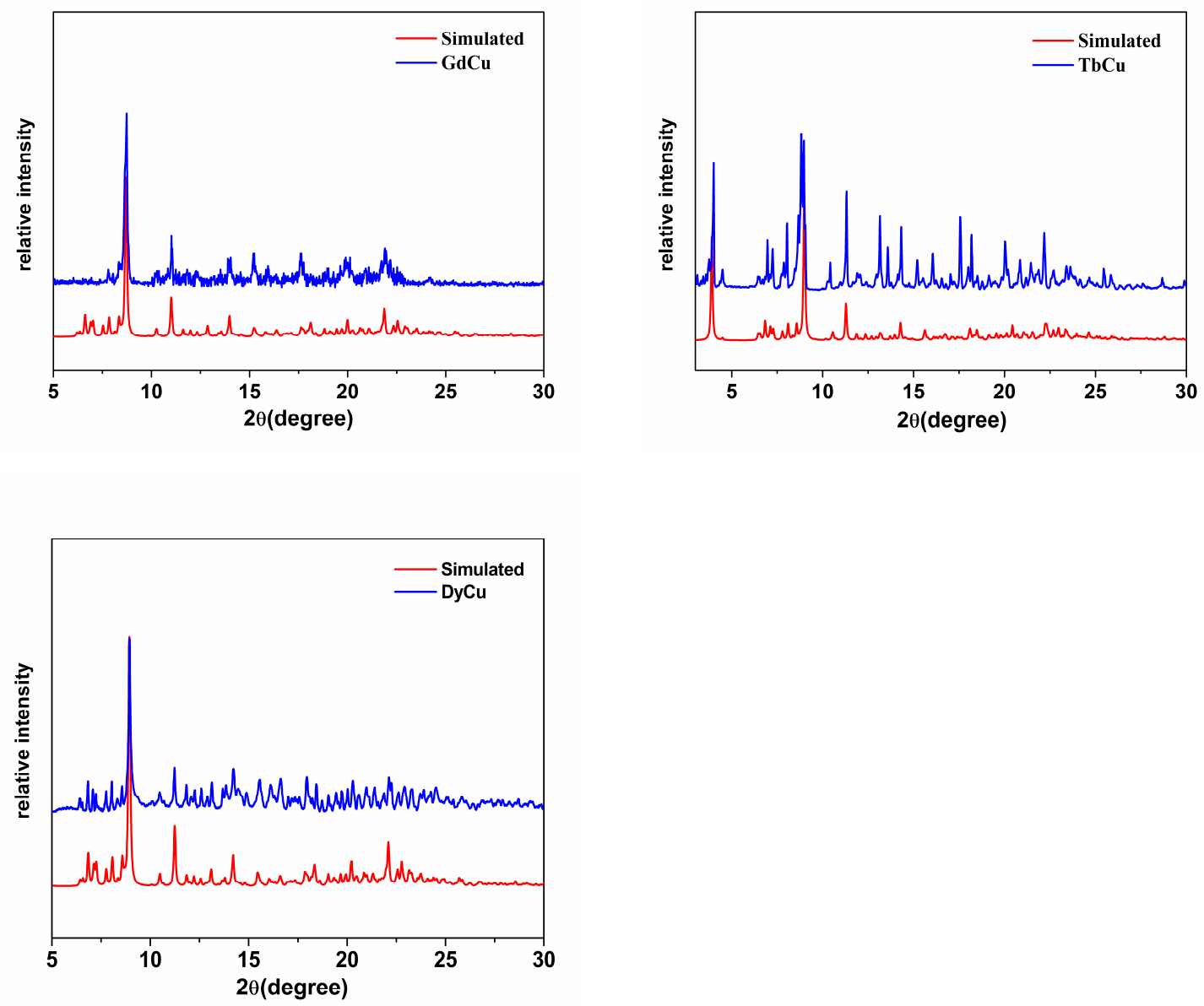

Fig. S9 Powder X-ray diffraction patterns of complexes 1-3.

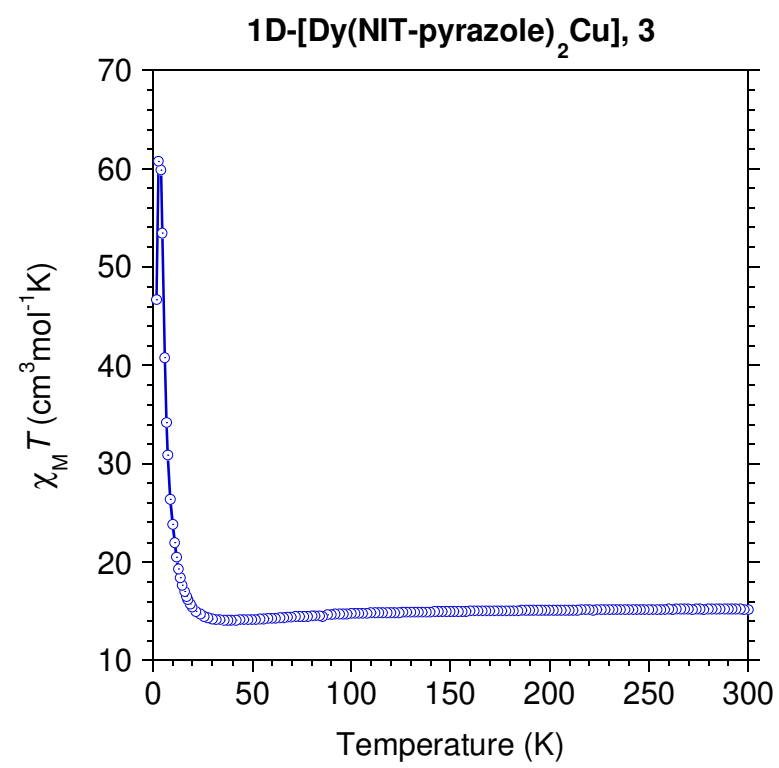

Fig. S10 Plot of $\chi_{\mathrm{M}} T$ versus $T$ for $\mathbf{3}$. 

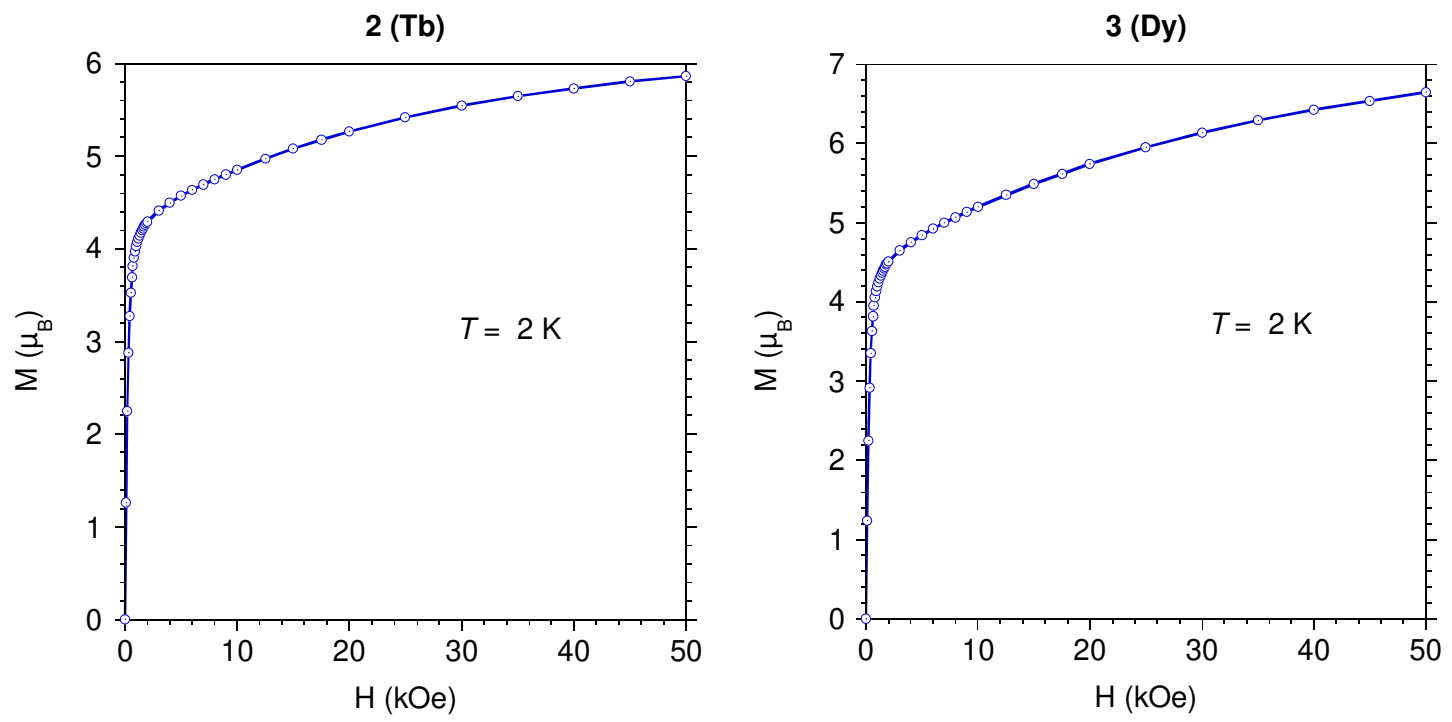

Fig. S11 Field-dependent magnetization for (left) 2 and (right) 3 at 2 K.
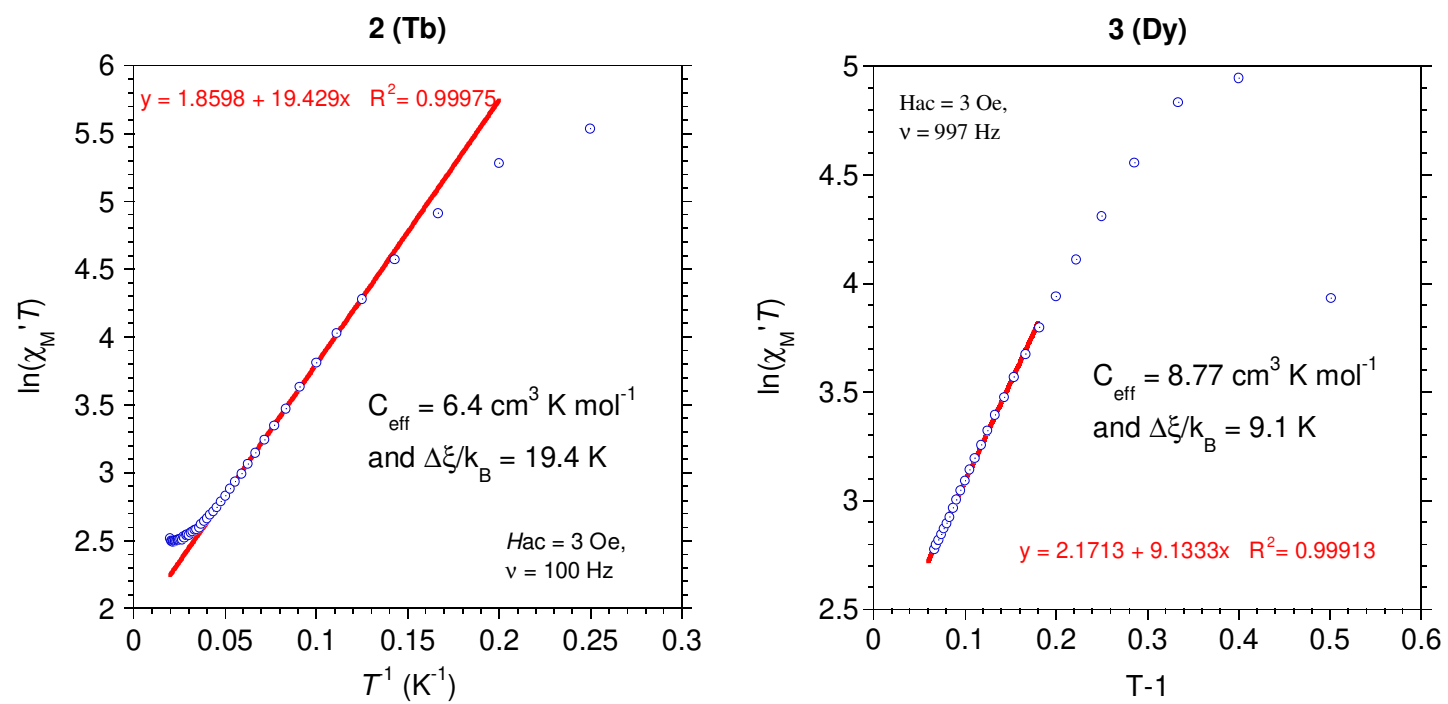

Fig. S12 Plot of $\ln \left(\chi_{\mathrm{M}}{ }^{\prime} T\right)$ versus $1 / T$ recorded in zero-field for (left) 2 and (right) 3; the solid red line is the best fit of the Glauber's expression to the linear part 8-23 K for 2 and 5-15 K for 3 . 

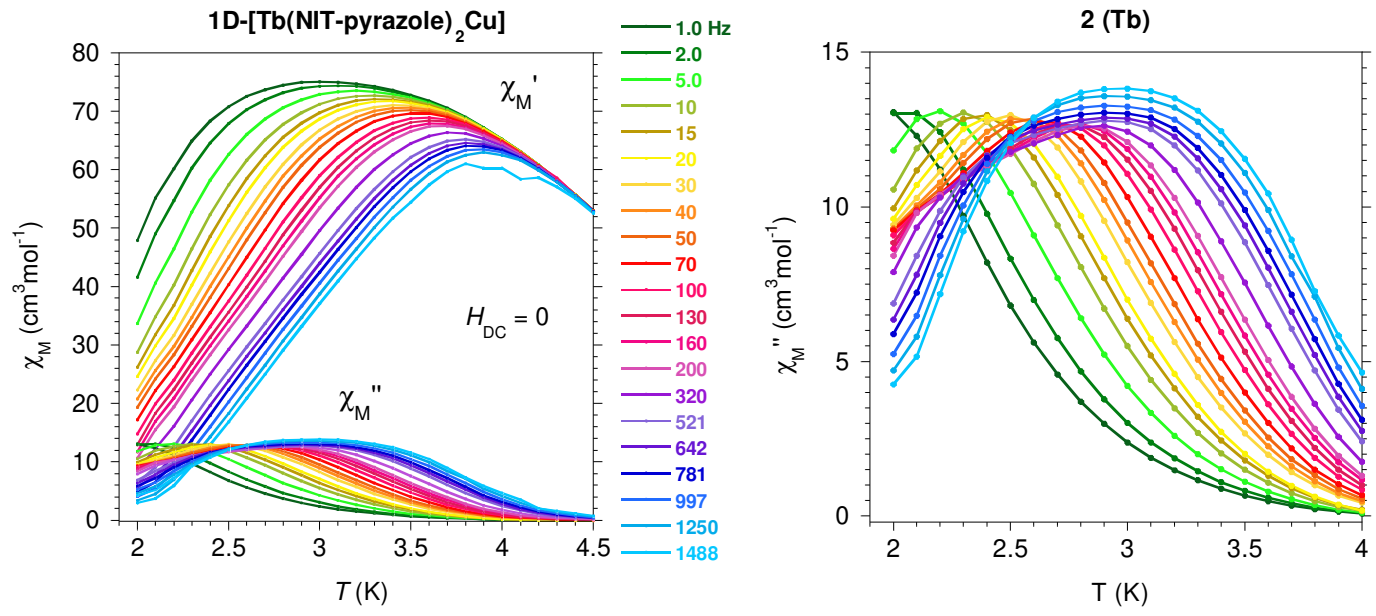

Fig. S13 (left) Temperature of the AC susceptibility for 2 in the frequency range 1-1488 Hz in zero field for compound 2 ; (right) detail of the $\chi_{\mathrm{M}}{ }^{\prime \prime}$ versus $T$ behavior.
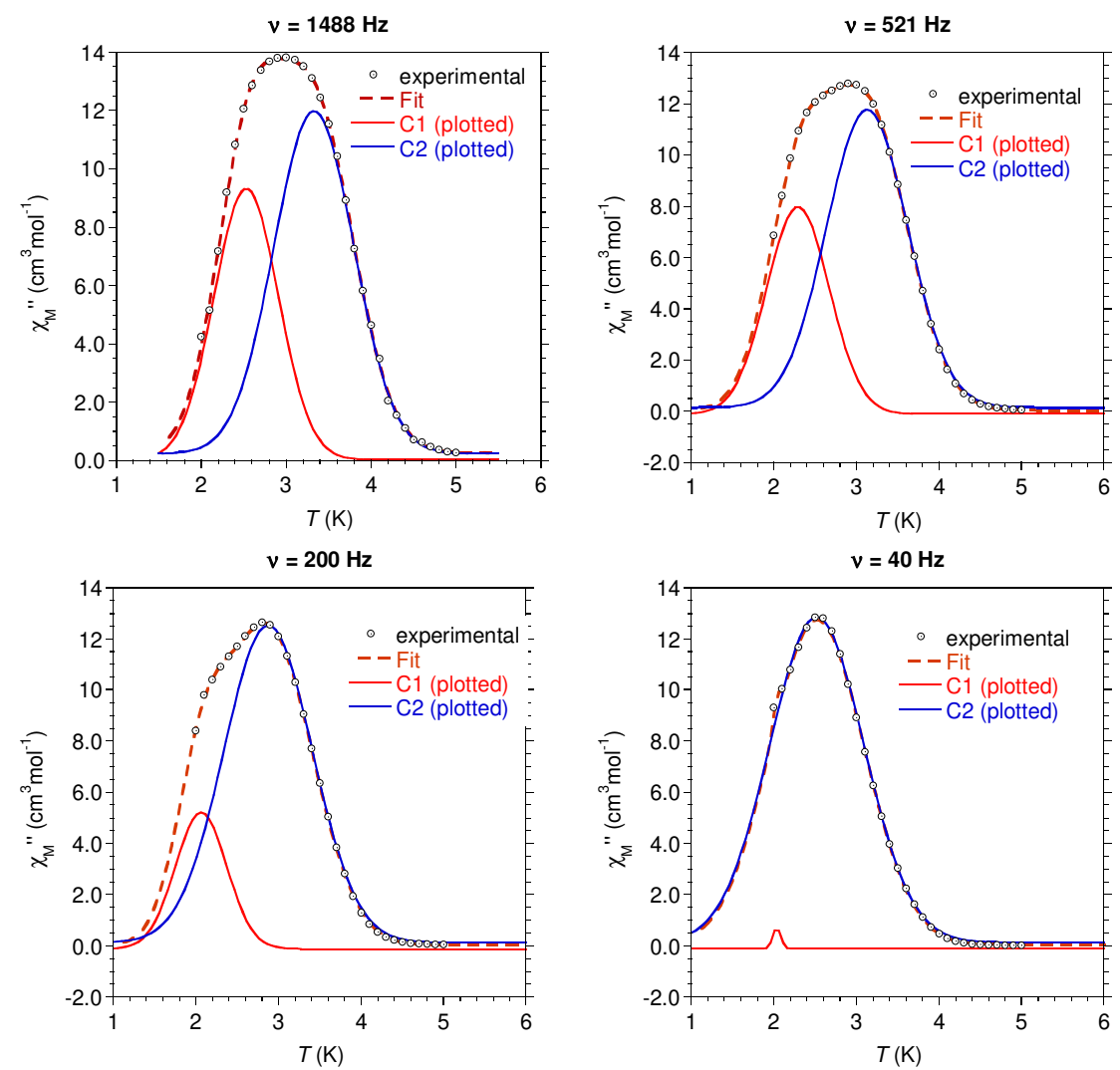

Fig. S14 Selection of deconvolution of $\chi_{\mathrm{M}}{ }^{\prime \prime}$ versus $T\left(H_{\mathrm{DC}}=0\right)$ for $\mathbf{2}$ for different frequencies. The dashed line is the fit of two Gaussian functions; $\mathrm{C} 1$ and $\mathrm{C} 2$ have been plotted with the best-fit parameters. 

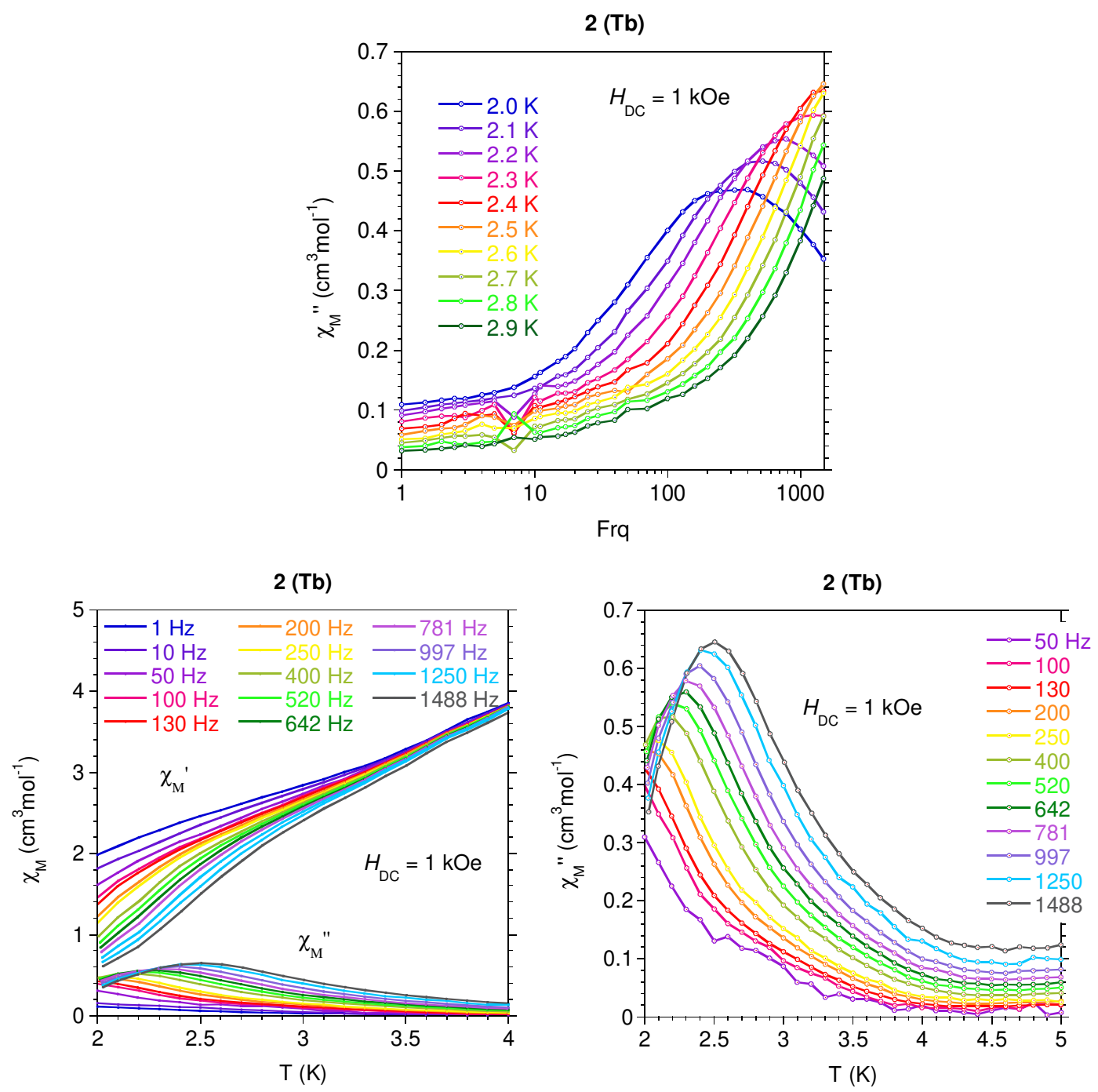

Fig. S15 Temperature and frequency dependence of $\chi_{\mathrm{M}}{ }^{\prime}$ and $\chi_{\mathrm{M}}{ }^{\prime \prime}$ for $\mathbf{2}$ in $H_{\mathrm{DC}}=1 \mathrm{kOe}$
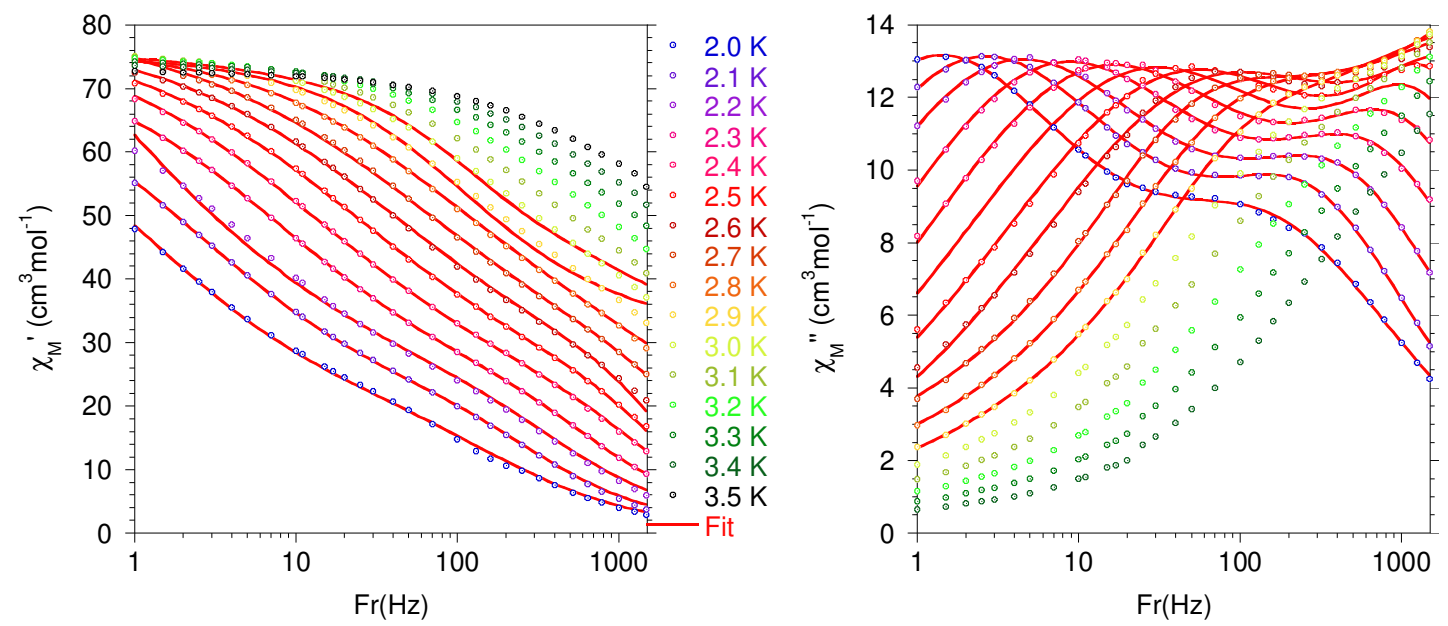

Fig. S16 Experimental $\chi_{\mathrm{M}}{ }^{\prime}$ and $\chi_{\mathrm{M}}{ }^{\prime \prime}$ versus frequency for 2 (in zero field) with best fit (full red lines, for data from 2.0 to $2.8 \mathrm{~K}$ ) of an expression of two Debye models to account for the two relaxation processes. The resulting $\tau$ values are given in Figure $6 \mathrm{c}$. 


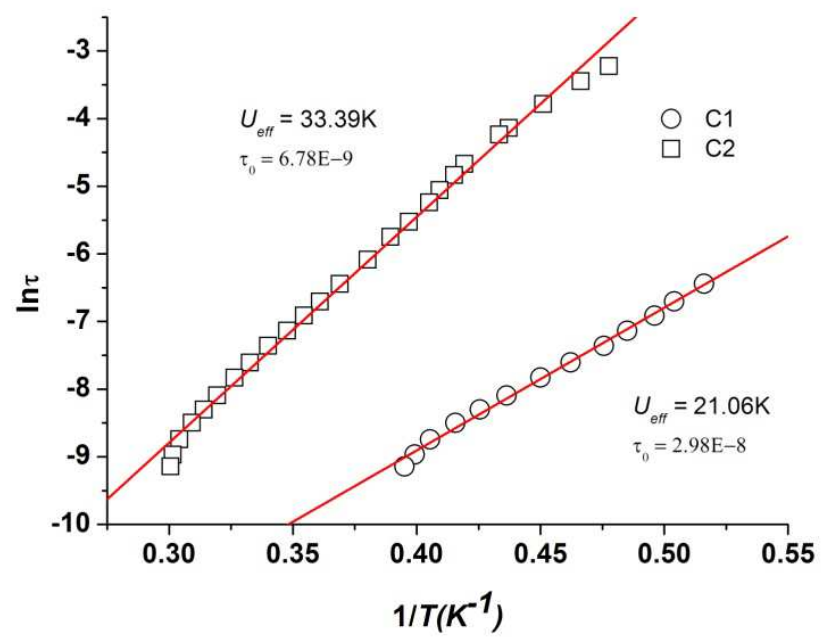

Fig. S17 $\ln \tau$ versus 1/T plots for compound 2 and best fit (solid lines) of the Arrhenius law. The $\tau$ values have been derived from the $T$ of the maximum of $\mathrm{C} 1$ and $\mathrm{C} 2$ components deconvoluted from experimental $\chi_{\mathrm{M}}{ }^{\prime \prime}$ versus $T$ behaviors.

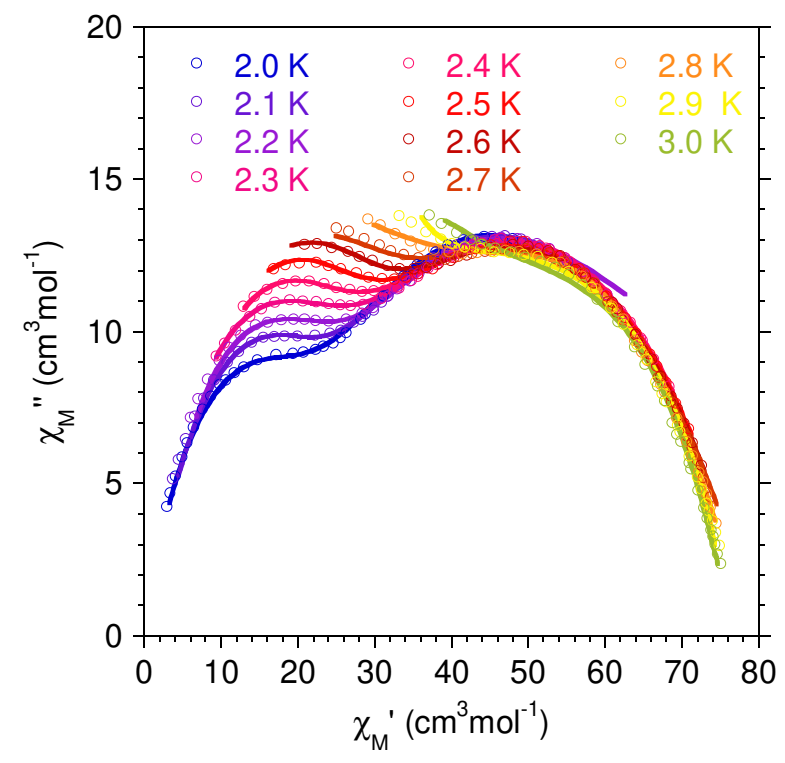

Fig. S18 Cole-Cole plots with best fits (full lines). The distribution widths of the relaxation times, $\alpha$, are large, ranging from 0.12 to 0.33 for $\mathrm{C} 1$ and 0.41 to 0.51 for the SCM (C2), likely resulting from the merging of the two data sets. 

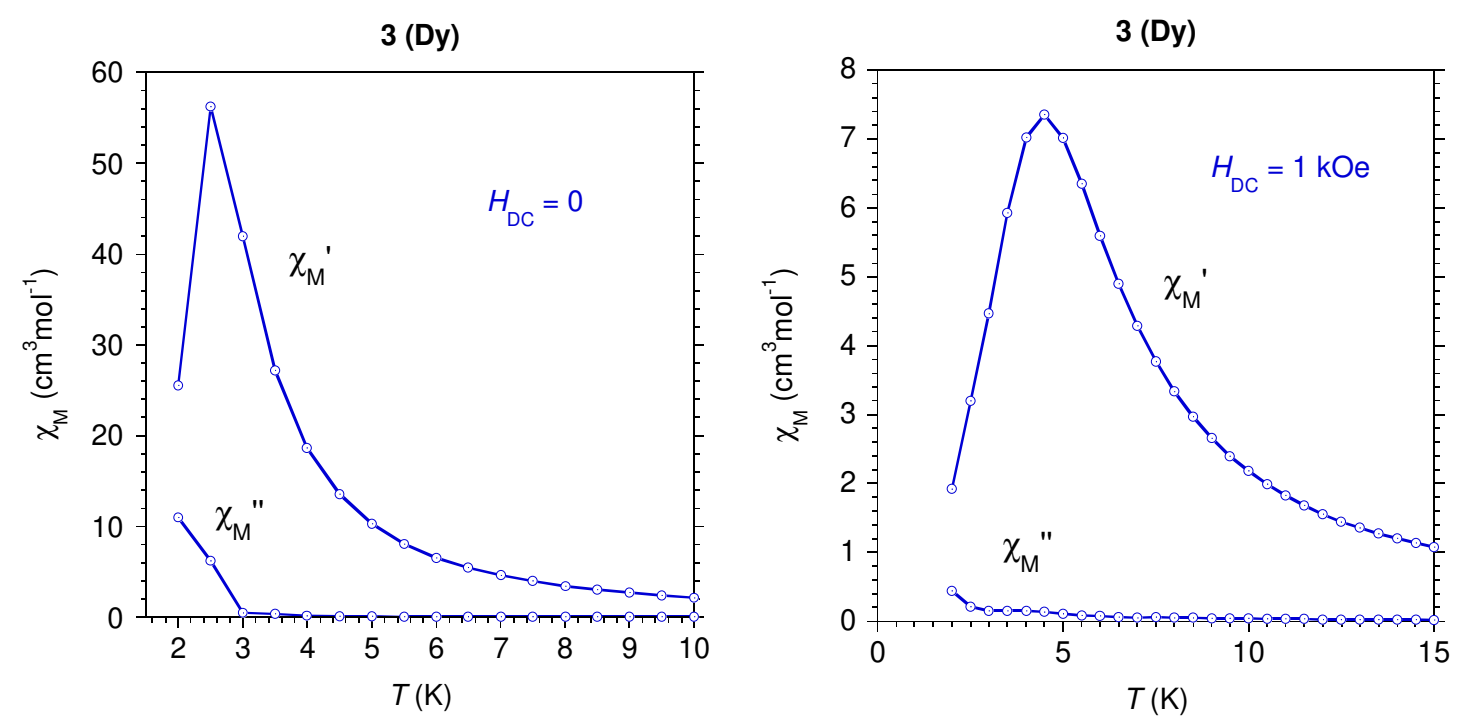

Fig. S19 Temperature-dependent ac signals of the $\chi_{\mathrm{M}}{ }^{\prime}$ and $\chi_{\mathrm{M}}{ }^{\prime \prime}$ for compound 3 in (left) zero field and (right) $H_{\mathrm{DC}}=1 \mathrm{kOe}$ field. 